(2) norden 



\section{Risk-based official control of the food chain}

Report from the project:

"Principles for risk-orientation of official control of food, feed, animal health and animal welfare" 
Risk-based official control of the food chain

Report from the project: "Principles for risk-orientation of official control of food,

feed, animal health and animal welfare”

TemaNord 2007:524

(C) Nordic Council of Ministers, Copenhagen 2007

ISBN 978-92-893-1474-9

Print: Ekspressen Tryk \& Kopicenter. Only available as print on demand

Printed on environmentally friendly paper

This publication can be ordered on www.norden.org/order. Other Nordic publications are available at www.norden.org/publications

Printed in Denmark

Nordic Council of Ministers

Store Strandstræde 18

DK-1255 Copenhagen K

Phone (+45) 33960200

Fax (+45) 33960202

www.norden.org

\section{Nordic Council}

Store Strandstræde 18

DK-1255 Copenhagen K

Phone (+45) 33960400

Fax (+45) 33111870

\section{Nordic co-operation}

Nordic cooperation is one of the world's most extensive forms of regional collaboration, involving Denmark, Finland, Iceland, Norway, Sweden, and three autonomous areas: the Faroe Islands, Greenland, and Åland.

Nordic cooperation has firm traditions in politics, the economy, and culture. It plays an important rol in European and international collaboration, and aims at creating a strong Nordic community in a strong Europe.

Nordic cooperation seeks to safeguard Nordic and regional interests and principles in the global community. Common Nordic values help the region solidify its position as one of the world's most innovative and competitive. 


\section{Contents}

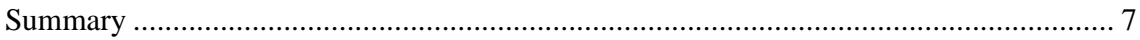

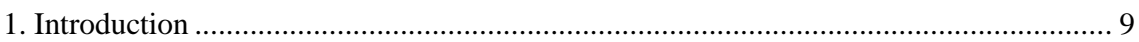

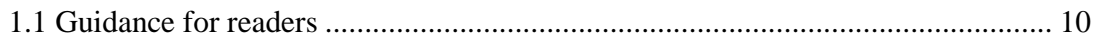

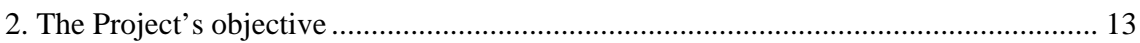

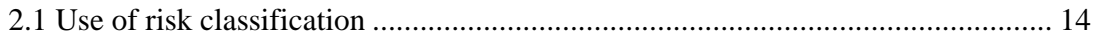

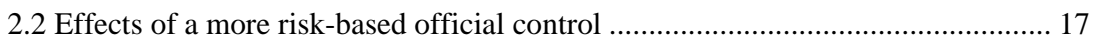

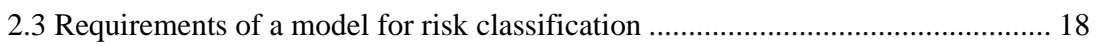

2.4 The limitations of the proposed model for risk classification............................... 18

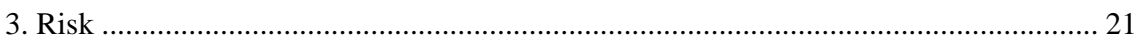

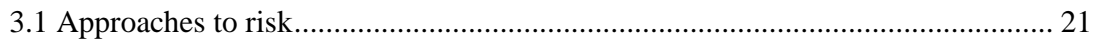

3.2 Identification of risks in relation to EU-Regulation 882/2004............................ 22

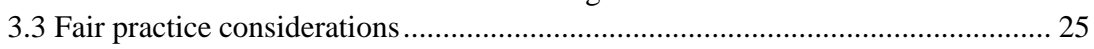

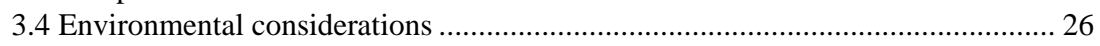

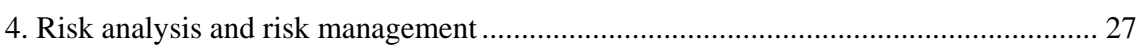

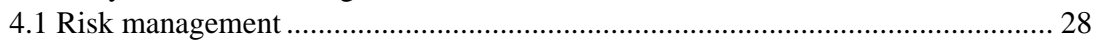

4.2 Risk-based or experience-based prioritisations ................................................. 28

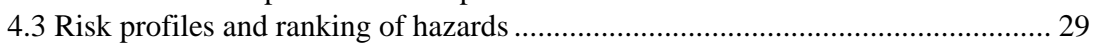

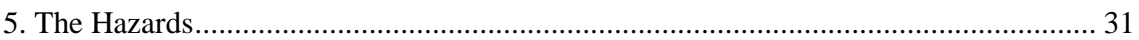

5.1 More detailed description of the hazard categories .......................................... 32

5.2 Unfair practice........................................................................................................ 34

6. The Food Chain Approach............................................................................................ 35

6.1 Comprehensive description of the chain in the form of industries ....................... 37

6.2 Do import activities belong in the food chain? ...................................................... 39

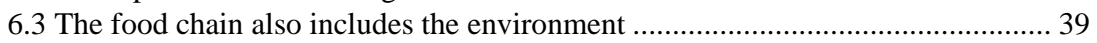

6.4 The food chain does not include activities in the private home ............................. 39

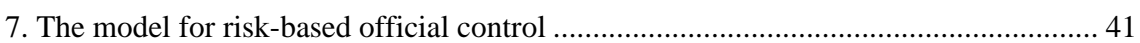

7.1 Purposes and premises..................................................................................... 41

7.2 Elements in the risk classification of businesses .................................................. 42

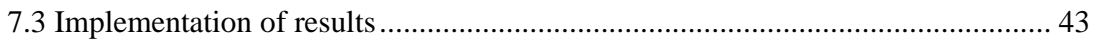

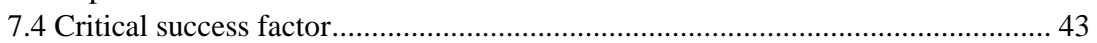

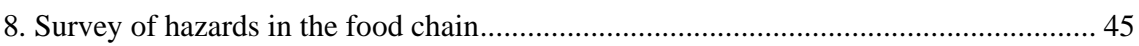

8.1 Recommendation of the analytical process ..................................................... 46

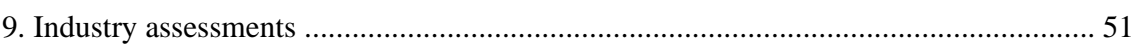

9.1 The requirement for assessments is variable ........................................................ 51

9.2 Proposal on the process for industry assessment ............................................... 51

9.3 Identification of risks and hazards associated with the industry .......................... 52

9.4 Development of risk profiles for industries ...................................................... 52

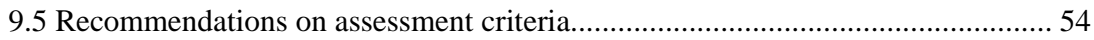

9.6 Critical success factors for development of risk profiles .......................................... 59

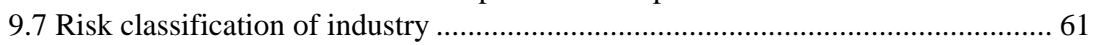




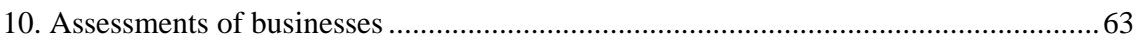

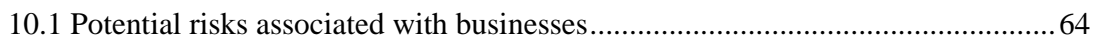

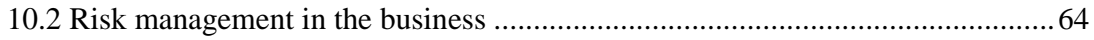

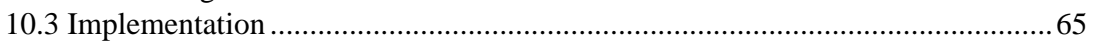

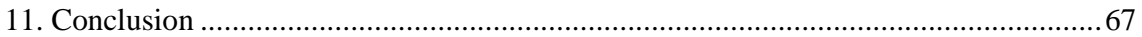

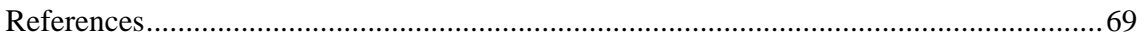




\section{Summary}

According to EU-Regulation 882/2004, official control of feed and food law, and animal health and animal welfare rules, and plant health directives shall be undertaken regularly, on a risk basis and with appropriate frequency, so that the Regulation's objectives are achieved.

The intention of this project was to develop a simple model for risk classification of all types of businesses included in the named directive, which can be used for prioritisation of resources for official control of businesses. The model is based on the premise that such prioritisation must be built on the knowledge available at any time.

An attempt is made to implement the concepts of public health risk, animal welfare risk, animal health risk, and plant health risk. The most important hazard categories are identified. Some assessments are also made of the possibilities of approaching fair practice considerations by the same method.

The model for risk classification is based on the food chain approach. The food chain is represented diagrammatically.

A process for risk classification of businesses is recommended. The process is divided into three steps:

1. Survey of hazards in the food chain (national assessment);

2.Industry assessments (national assessments);

3. Assessments of businesses (local assessments).

In surveying the food chain, all the principal hazard groups and control points in the chain are identified. The hazards are associated with particular industry groups or industries. It is furthermore identified where official control of the various hazard groups is most important.

During the industry assessment, risk profiles are developed and assessment of the risks associated with appropriate groups of businesses (industries). The industries are classified into 4 risk classes. Within each industry, points of focus for official control or supervision (points in which it is most important to have official control) are identified.

For business assessments, the separate businesses are assessed individually, and these assessments are conducted in tandem with official inspection. The risk associated with a business is assessed as high, normal, or low in comparison to the industry average for that business. High risk indicates that that particular business is classified in a risk class above that stipulated for that industry. Low risk indicates that that particular business is classified in a risk class below that stipulated for that industry. 
For businesses that encompass several industries, the risk is classified in comparison to that industry which has the highest risk classification.

The risk classification is employed to determine the extent of official control for industries and individual businesses, based on standards that the individual control authorities decide. The points of focus for official control or supervision are used to establish how controls are conducted within the individual industries.

The critical factors to ensure success with this proposed model are as follows:

- Results are continuously maintained and regularly evaluated;

- Good management systems, data applications etc.;

- Development of a mature risk culture.

This report is also available in Norwegian. 


\section{Introduction}

This project was conducted with support from the Nordic Council of Ministers. The project was conducted between August 2005 and December 2006. The project group was comprised of the following members:

- Helge Løtveit (project leader), Norwegian Food Safety Authority

- Ann-Christine Salomonsson, National Food Administration (Sweden)

- Mads Kolte-Olsen, Danish Veterinary and Food Administration

- Liisa Niemi, Finnish Food Safety Authority Evira

- Balvin Valgardsson (up to and including 31.01.2006), Environment and Food Agency of Iceland

- Ingólfur Gissurason (from and including01.02.2006), Environment and Food Agency of Iceland

Additionally, the following have participated in the meetings:

- Katarina Andersson (up to and including 07.02.2006), Swedish Animal Welfare Agency

- Alexandre Barchiesi (from and including 08.02.2006), Swedish Animal Welfare Agency

There have been 10 project meetings of the project group. Additionally, the project has been presented at a meeting of the Nordic work group for animal health and welfare (NDD). On request from NDD, the project group has conducted a workshop on risk-based official control of animal welfare.

Within the same period (August 2005-December 2006), a Norwegian group has conducted 23 project meetings, and three larger workshops on the same theme as addressed in the Nordic project. The Norwegian group was comprised of:

- Helge Løtveit (leader), Norwegian Food Safety Authority

- Marit Nilsen, Norwegian Food Safety Authority

- Rolf Horntvedt, Norwegian Food Safety Authority

- Malin E. Florvåg (up to and including 31.12.2005), Norwegian Food Safety Authority

- Maria Melstokkå (from and including 01.01.2006), Norwegian Food Safety Authority

- Erik K. Bergh (up to and including 31.05.2006), Norwegian Food Safety Authority 
- Rolf Haugland (from and including 01.06.2006), Norwegian Food Safety Authority

- Magnar Katla (from and including 15.05.2006), Norwegian Food Safety Authority

During the course of the work there have been ongoing exchanges of ideas between these two groups. It has been of considerable advantage to the project to have access to the work conducted by the Norwegian group.

The project has attempted to build upon a solid foundation of accepted knowledge. Few of the ideas that are presented in this report are new, and much is re-use of that which has previously been undertaken by others. That which is new in this report is the method by which it has been attempted to incorporate accepted knowledge into a system, and implemented in order that it can be used to fulfil the requirements of EURegulation 882/2004 for risk-based official control. To our knowledge, development of models or systems for prioritising use of resources for official control, covering all the areas included in EU-Regulation 882/2004, has not previously been attempted.

This English version of the report is presented without appendices. When appendices are mentioned to in the text, these refer to the Norwegian version of the report. Classification of industries in English can be found by consulting Statistics Norway (2003) and checking the relevant NACE codes provided.

\subsection{Guidance for readers}

Chapter 3 describes what can be achieved from a risk orientation of official control, and which requirements should be included in a model for risk classification in order to achieve the desired effects.

Good risk management assumes that the risks that will be managed have been identified and specified. In Chapter 4 we have attempted to define the risks that are encompassed by EU-Regulation 882/2004, in such a manner that they can be implemented in a model for risk classification.

Chapter 4 is a theoretical chapter on risk management, where the risk classification is set in context in relation to the FAO/WHO model for risk analysis. The problems associated with risk-based and experience-based prioritisation are also mentioned.

Chapter 5 elucidates the concept of hazard and the most important hazard categories are identified in relation to EU-Regulation 882/2004.

Chapter 6 clarifies what is meant by the food chain approach and the food chain is described.

Chapter 7 provides a brief presentation of the model for risk classification. This is based upon the structure that has been developed in Chap- 
ters 3, 5 and 6. Therefore, understanding of the model assumes a clear comprehension of the contents of these chapters.

Chapters 8-10 contain a closer description of the three most important elements in the model:

1. Surveying of hazards in the food chain;

2. Industry assessments;

3. Assessments of businesses.

These three steps are presented diagrammatically overleaf. It could be helpful to use this diagram as a reference point whilst reading the report.

In the conclusion, future prospects are considered. Here, amongst other issues, aspects for further development are identified. 


\section{Survey for hazards in the chain}

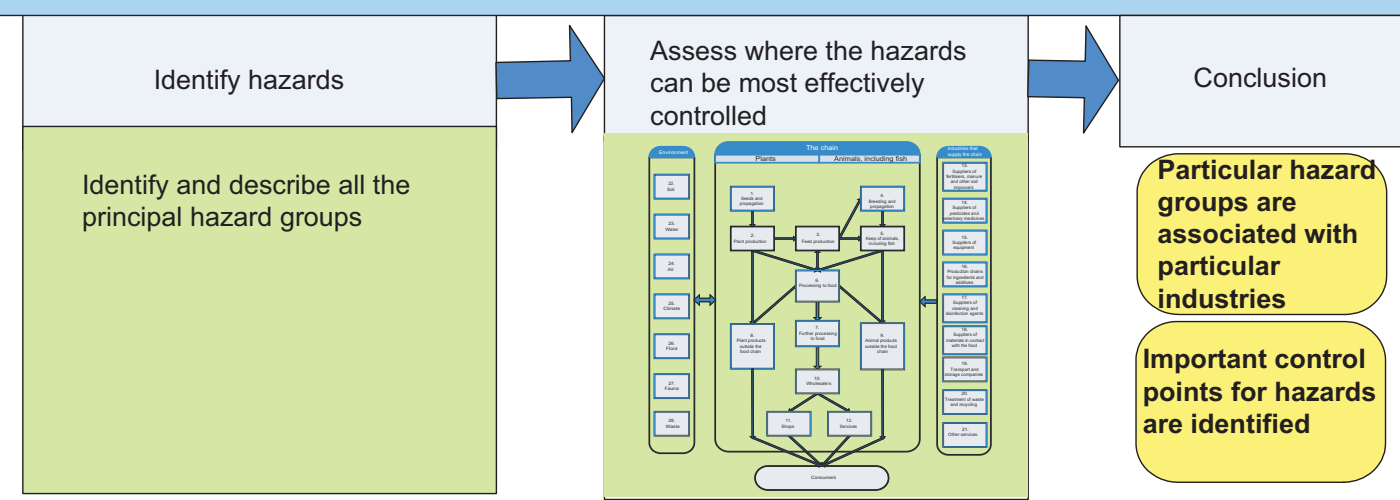

\section{Industry assessment}

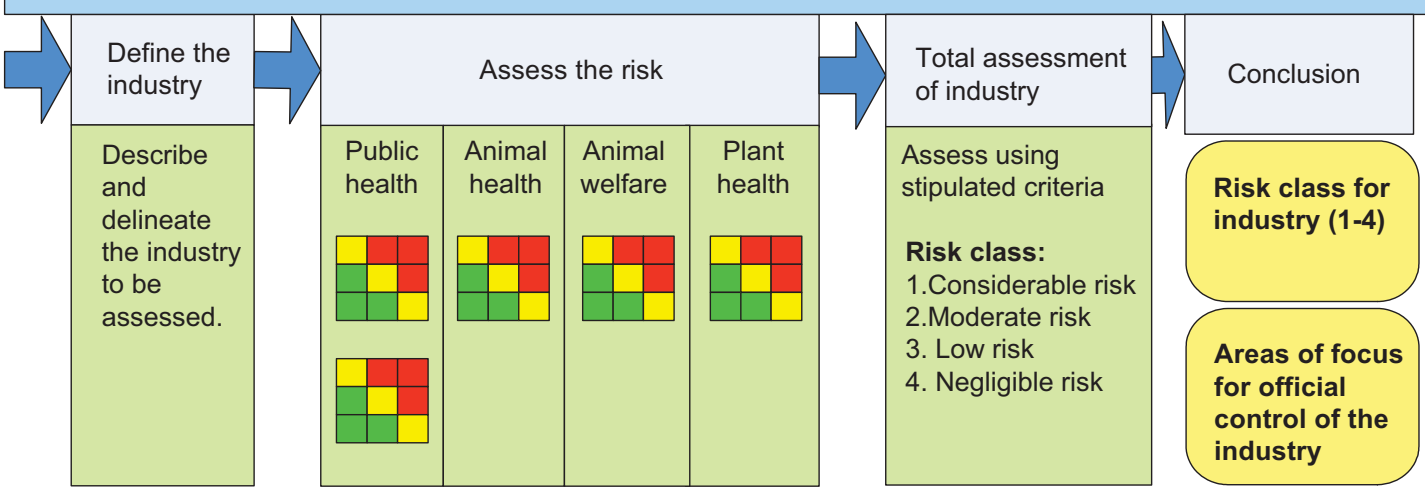

\section{Assessment of business}

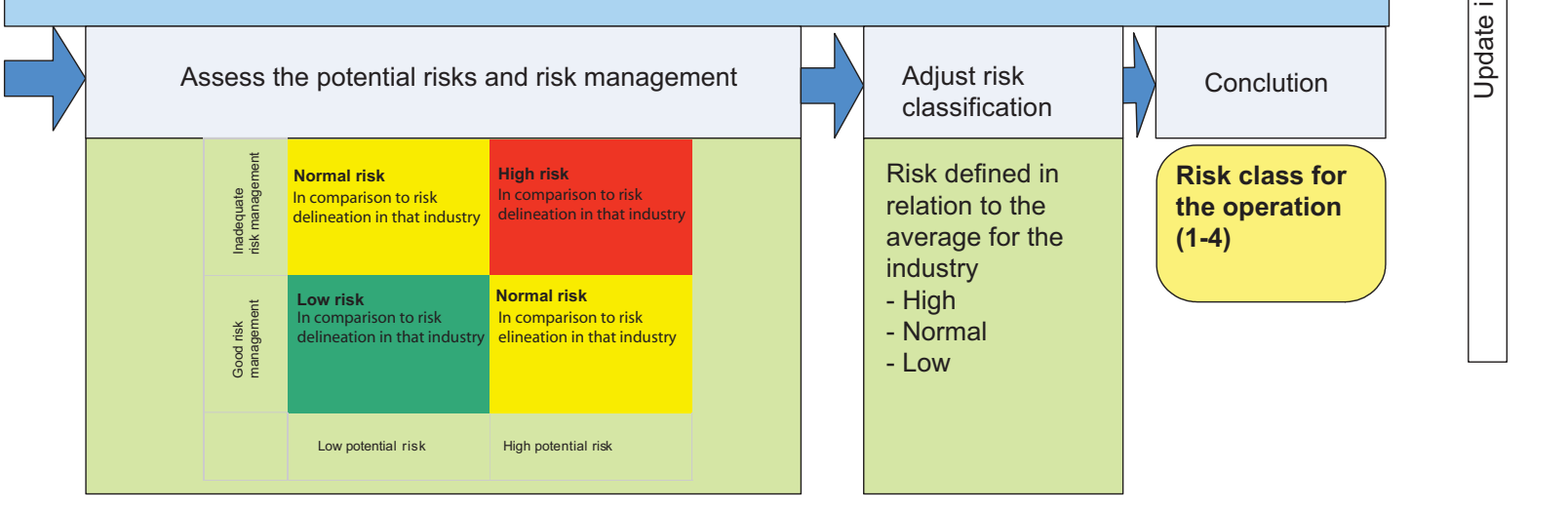

Figure 1. The risk classification process 


\section{The Project's objective}

The European Parliament and The Council of The European Union (2004), have, in Regulation nr 882/2004, stipulated general rules regarding official control of directives for feed, food, animal health, and animal welfare, with a view to:

a. Preventing, eliminating or reducing to an acceptable level, risks to both humans and animals, either directly or through the environment; and

b. Guaranteeing fair practices in feed and food trade, and protecting consumer interests, including feed and food labelling, and other forms of consumer information.

Via Article 59 of EU-Regulation 882/2004, the area of plant health is also included in the Regulation's requirement for risk categorisation.

Member states shall ensure that official control is undertaken regularly, on a risk basis and with appropriate frequency, so that the Regulation's objectives are achieved (cf. Article 3 of the Regulation). Multiannual control plans shall contain general information on the risk categorisation of the relevant activities (cf. Article 42.2).

All the Nordic countries have systems in place for risk-based official control of food. Several of these are based on the system developed by the Australia New Zealand Food Authority (2001). However, none of the Nordic countries currently have systems in place for risk classification of operations that cover the entire field encompassed by EU-Regulation $882 / 2004$.

The intention of this project was to develop a simple model for risk classification of all types of business that are included in the feed, food, animal health, animal welfare and plant health directives. Furthermore, emphasis was placed on developing a model that can be used in different countries, with different organisations and with different prioritisation of the tasks for control. It is assumed that each individual country will develop solutions for adjusting and using the model for its own particular circumstances and needs.

The model also attempts to implement the Food Chain Approach, based on principles from FAO (2003).

The model that is presented in this report is idealistic, in the sense that it assumes optimal organisation of the official control and well developed resources, in order for the model to function optimally. The project group would like the model to be a device that the organisations in all the Nordic countries can begin to work with, and strive towards, without conside- 
ration of how they are currently organised, and the present availability of resources etc.

This project is limited to how a control authority can take into consideration the identified risks by division of resources to official control in order to ensure the verification of compliance with feed and food law, animal health and animal welfare rules (cf. definition of 'verification' in Article 2, point 2 of EU-Regulation 882/2004). The project has not assessed how organisations should interact with the scientific fields concerned with risk assessments, nor how the control authorities can address the identified risks through legislation and organisation structure.

\subsection{Use of risk classification}

Risk management is a process in which knowledge about a risk is used to reach better decisions. The risk approach enables the uncertainty to be placed in focus in a pro-active manner, so that threats are minimised, possibilities are maximised and the objectives are achieved and optimised.

\subsubsection{Risk categorisation is a pre-condition in order to differentiate between businesses for official control.}

In Article 3.1 of EU-Regulation 882/2004, conditions are listed that should be considered with respect to the establishment of the frequency of control:

a. Identification of risks associated with animals, feed or food, feed or food businesses, the use of feed or food or any process, material, substance, activity or operation that may influence feed or food safety, animal health or welfare;

b. Feed or food business operators' past records as regards compliance with feed or food law or with animal health and welfare rules;

c. The reliability of any own checks that have already been carried out; and

d. Any information that might indicate non-compliance.

Additionally, our community has developed rules of law to protect traders against arbitrariness from officials. These ensure effective administration and management. This last consideration means that the official control authorities will, as a rule, need to differentiate between official control of industries and of businesses. An effective, appropriate and flexible official control is not possible without a preliminary assessment as a basis for risk categorisation. Openness concerning the control authorities' work methods and assessment criteria is the most important tool for ensuring against arbitrary or high-handed treatment of the traders. Differentiated 
control between different industries, or between different traders within the same industry, will be difficult to justify unless the authorities are able to state those criteria that are responsible for the differentiation.

\subsubsection{Risk categorisation is a tool to improve security}

Risk categorisation can be used as a tool to attain greater security through:

- Better direction of resources towards those areas and links in the food chain where the effects achieved by official control are greatest;

- Employment of common assessment criteria that results in a more systematic and effective performance;

- Employment of more appropriate methods in relation to different hazards and problems within the food chain.

The authorities can influence levels of risk through:

- Stipulated rules and norms for acceptable risk;

- Setting risk in focus and ensuring it is a central point of attention;

- Providing a pro-active influence of risk management in businesses through requirements for own checks, and conducting audits, and other types of control;

- Directing resources towards those areas where the risks are greatest or there are the best opportunities for affecting them;

- Fees or charges can also be used as incentives to combat risks.

The effects of control are assumed to be greatest in most cases if the problems are addressed as they occur. Where it lends itself to this, control should be aimed at being as early as possible in the food chain. Identification of those areas and links in the food chain where the effects of official control are assumed to be greatest can also be used to develop better indicators and key figures to measure the effects of the control and provide better data for further planning.

Improved databases and communication of the control authorities' priorities and work methods will hopefully also provide another approach that can contribute towards further training and improvement, and greater flexibility in the organisations.

\subsubsection{Risk categorisation can be used for deciding upon national distribution of resources}

In deciding upon the national distribution of resources for official control, several considerations must be assessed: 
- Documented risk;

- Possibilities for reducing the risk, and the cost-benefit effect of possible approaches;

- Political considerations (the political agenda etc.);

- Strategic considerations.

Apportioning of the control-contribution has often been made on the basis of a combination of professional assessment, experience, tradition and political considerations. Therefore, the approach to risks has often been unstructured. However, the requirement of EU-Regulation 882/2004 for a combined prioritisation of contribution entails that the reasons for these decisions must be more transparent, and the individual criteria for decision-making must be made explicit.

The Nordic control authorities working within the areas of food, feed, animal health, animal welfare and plant health are confronted by various challenges when they are required to make a more risk-based distribution of resources between different areas of effort. In some Nordic countries, the distribution will be largely decided on a political basis. In other countries, the control authorities will be given a framework for the distribution, together with a set of political guidelines.

Risk categorisation will be, first and foremost, a contribution to the professional basis for the assessment that shall be undertaken in a manner that is more explicit, more fact-based and more transparent. In some respects, the distribution of resources will reflect the distribution of risk within the food chain, assuming a minimum of consensus. Sensible prioritisation of resources to official control is not possible without the following:

- That it is based upon a prior dialogue (cooperation and coordination, discussion of different points of view) between official authorities at different levels and between different links in an organisation;

- That it contains prioritisation of official control of different types of activities or industries.

Risk categorisation can be used to provide the grounds for, and to support, the proposal to alter the division of resources to official control of different types of activities or industries, and thus the ability to alter the organisations themselves.

The project group, meanwhile, considers it important to point out that the model for risk classification has not been developed with a view to estimating resource requirements, but to be used as a tool to enable prioritising within the prevailing resource framework at any time. 


\subsubsection{Use of risk categorisation for prioritisation of official control of individual traders}

Risk classification can be used to prioritise official control of businesses. Good national management systems and data applications are assumed to be in place in order for effective utilisation of risk classification data of an individual business, in order to prioritise items for official control. The project has developed a model for risk classification, but does not propose any process or technical solutions for selecting objects or items for control, based upon that classification. It is assumed that individual countries will develop their own solutions for this, most suited to their individual management systems and data applications.

\subsection{Risk categorisation can be a component of the decision-making} basis by assessing the requirement for legislation

During the process of risk categorisation, it is also possible to identify hazards and activities that are improperly regulated as a consequence of changes in market conditions, production conditions etc. Furthermore, these processes might also reveal national regulations that are no longer in proportion to the risk. This might, for example, concern national sanctions or approvals. A risk categorisation process can thus be used to initiate new ideas, rather than for simply cementing in place that which is already there.

\subsection{Risk categorisation can be a component of the decision-making} basis by establishing fees or charges

Article 27, point 5, of EU-Regulation 882/2004 provides a list of factors that should be considered by the EU member states when establishing fees or charges. Amongst other factors, consideration should be given to the type of business concerned and relevant risk factors.

Article 27, point 6, of EU-Regulation 882/2004 also provides the possibility for reducing the fees or charges associated with certain types of food or feed businesses in reliable cases. This arrangement can, among others, be used in cases where good risk management in the business results in a reduction in the frequency of official control.

\subsection{Effects of a more risk-based official control}

The project group has worked with a view to the departments in the Nordic countries eventually being able to achieve the following effects from a more risk-based official control. 
1. Greater security;

2. A more systematic and effective performance;

3. A more transparent and equal official control;

4. A better basis for establishing fees or charges;

5. Improved evaluation of the effects of official control;

6. Improved utilisation of knowledge or information about risks and compliance with the laws and rules;

7. Increased flexibility;

8. Increased competence for addressing problems associated with risk.

In some instances the results from the risk categorisations could also be used as a part of the basis for decisions on assessing the requirement for legislation.

\subsection{Requirements of a model for risk classification}

In order to achieve this, the project group has laid as a basis that the model and processes for risk classification should satisfy the following requirements.

- It should be possible to incorporate the model into the organisation's management or planning systems;

- The model should be sufficiently simple that it can be implemented via web-based approaches;

- The model should take into consideration management measures in the industries or individual businesses;

- The processes must be dynamic, so that gradual changes in risk over time can be incorporated;

- The processes should be arranged such that official control and use of other tools/incentives used to achieve compliance with the legislation can be seen in connection to each other;

- The inspectors should be able to use the results as support during the execution of control;

- The model should support continuous learning and improving (planning, performing, evaluating and improving).

\subsection{The limitations of the proposed model for risk classification}

The model, which is presented later in this report, has been developed with a view to prioritisation of resource requirements within the framework at any given time. It has not been developed for use in estimating resource requirements, nor has it been developed for handling crises. 
The model encompasses only those risks associated with health and welfare. However, it is possible to develop the model further, such that it also encompasses fair practice, quality and environmental considerations.

Food safety is increasingly becoming an international concern. With respect to selecting risk levels, it is probable that there will always be tensions between international harmonisation and national sovereignty. Much of resource use associated with official control of the food chain is governed by international standards and legislation. This report assumes that international obligations concerning risk handling take precedence over national priorities. International requirements on, for example, frequency of control, will take precedence in relation to the assessments of risk levels undertaken with assistance from the model presented in this report.

The quality of risk management can never be better than the knowledge or information available concerning the risks. The model is based on the fact that prioritisation concerning official control must be built on the knowledge available at any given time, and not on the basis of knowledge that is being worked towards obtaining at some point in the future. The project group considers that, at the time of writing, there is insufficient knowledge available on all the risks to enable risk-based prioritisation to be conducted in all the fields of interest. In the report both risk-based and experience-based priorities are discussed. The objective should be for risk-based prioritisation as much as possible. As greater knowledge about the various risks is acquired, the model should be further developed towards more risk-based prioritisations.

The model does not constitute some form of management system. It is only able to provide data and assessments for use within management processes. 



\section{Risk}

\subsection{Approaches to risk}

Precise definition of risk is a prerequisite in order to be able to assess and manage risk.

There are many types of risk; commercial risk, strategic risk, project risk, technical risk, security risk etc. In this report, the risk is only related to social objectives concerning safe processes, products and services.

Hillson et al (2005) wrote that there is no broad consensus on what is meant by the concept of risk. Many different definitions and underlying concepts exist. Despite the lack of consensus, there are two features that recur in all definitions: risk is associated with uncertainty, and risks have consequences. Until 1997, all official published standards for risk management used exclusively negative definitions of risk, where risk was regarded as an uncertainty that could have negative, harmful or undesirable effects with respect to one or several objectives. After 2000 most new or revised standards use risk concepts that include both threats and possibilities.

This report takes a traditional approach to risk, by putting in focus different objectives on safety. However, it does not exclude further development of the model at a later date to include possibilities also, for example, possibilities for better animal welfare or improvement in fair practice values.

In order to cover the complete field of EU-Regulation 882/2004, the project group has found it necessary to use general risk and hazard concepts. Based upon ISO/IEC (1999), the project has used the concepts of 'risk' and 'hazard' in the following senses:

Hazard: Potential source of harm

The hazard concept can also be used to define the type of harm in question (for example, harm caused by contaminants, animal diseases). In ISO/FDIS 22000 it is pointed out that the concept of 'hazard' must not be confused with the concept of 'risk'.

Risk: The combination of the probability of occurrence of harm and the severity of that harm

The concepts of risk and security/safety are closely related and can be considered as the two sides of the same equation. A high degree of risk is indicative of a small degree of safety/security, and vice versa. ISO/IEC (1999) describes "the concept of safety". This concept is based upon the following: 
a. Absolute safety can never be achieved. Some degree of risk will always remain, even after measures have been taken to reduce the risk. Therefore a product, process or service can only ever be relatively safe.

b. Safety is achieved by reducing the risk to a tolerable level. Tolerable risk is determined by reaching an optimal balance between the ideal of absolute safety, the demands to be met by a product, process or service, and factors associated with the product, process or service that benefit the user (e.g. user-friendliness, effectiveness etc.)

c. The approach is to attempt to reduce the risk that occurs from use of products, processes, and services. In this respect, it is necessary to assess the complete life-cycle of the product, process or service, from beginning to end, and including both using the product, process or service as intended, and also instances of reasonably foreseeable misuse of the product, process or service.

\subsection{Identification of risks in relation to EU-Regulation $882 / 2004$}

All human activities are conducted in order to achieve some type of objective. We do not know if undesirable events might occur during any activity, e.g. accidents. Thus we have uncertainty. It is this uncertainty that we describe as risk. The risk is 'somebody's risk' - it can be mine, ours or yours. A single type of event (for example, an accident) can represent a different risk for different parties; for example the individual who is affected directly by an accident and the insurance company of that individual. It is normally understood that the concept of risk is meaningless without it in some way being associated with someone's objectives or interests.

The project has attempted to identify risks, relevant to EU-Regulation $882 / 2004$, in respect of which, and whose, values are under threat. The project has identified three types of value that can be considered to be at stake. These are human (public) health values, animal welfare values (absence of suffering), and economic values. It is the combinations of the probabilities and consequences from loss or, or damage to, these values that the project group has identified as risks. The following risks are defined as relevant with respect to EU-Regulation 882/2004:

\section{Public health risk}

- Undesirable health effects for people caused by hazards associated with food, or by transmission of serious infectious animal diseases ${ }^{1}$ directly from animals to people.

\footnotetext{
${ }^{1}$ Serious infectious animal diseases are animal diseases that are subject to official restrictions regarding transmission.
} 
Animal welfare risk

- Unnecessary suffering of animals as a result of disease, or inappropriate keep or treatment of animals.

\section{Animal health risk}

- Economic consequences for society as a result of introduction or transmission of serious infectious animal diseases ${ }^{2}$, and dispersal of invasive species.

\section{Plant health risk}

- Economic consequences for society as a result of introduction and dissemination of regulated plant pests and invasive species.

\section{Public health risk}

Public health risk (cf. definition of risk in Regulation nr. 178/2002 (European Parliament and The Council of The European Union, 2002) and ISO/FDIS 22000 (ISO 2005)) is related to the occurrence of hazards in food or feed. A hazard is defined as "a biological, chemical or physical agent in, or condition of, food or feed, with the potential to cause an adverse health effect”. The hazard definition limits the content of the risk concept, both in relation to products and in relation to causes. For example, obesity and malnutrition problems are excluded.

The range of application of EU-Regulation 882/2004 encompasses more than only food and feed. Infection with zoonotic agents, directly from animals to people, can also represent a threat to human health. The project group has chosen to include such risks in their definition of public health risk.

\section{Animal welfare risk}

The project group has been unable to identify any internationally recognised theories, or suitable risk and hazard concepts, to address risks in relation to animal welfare.

The safety concept is not similarly applicable to the animal welfare field as it is to the fields of public health, animal health and plant health. The safety concept can be used to approach hazards associated with intended use and reasonably foreseeable misuse of products, processes and services. However, with respect to animal welfare there is an increasing number of problems that can be very difficult to predict.

The modern administration of animal welfare has as its objectives, promotion and advancement of the welfare of animals. This approach implies that the more recent concepts of risk (that also include possibili-

\footnotetext{
${ }^{2}$ See previous footnote (1)
} 
ties) can be of greater relevance to animal welfare than to the other areas of interest.

In their definition of animal welfare risk, the project group has attempted to include all the relevant circumstances that can result in unnecessary suffering to animals. This also includes suffering caused by animal diseases, physical agents, and contaminants.

\section{Animal health risk}

The World Organisation for Animal Health (2005) has defined risk such that it encompasses risks in relation to both human and animal health. Hazards, related to their occurrence in animal and animal-derived products, are defined in a similar manner to the way in which The European Parliament and The Council of The European Union (2002) has defined hazards related to food and feed.

This means that that these two definitions of risk overlap to some extent. The definition of risk used by the World Organisation for Animal Health appears difficult to implement in a model for risk classification. In order to avoid an individual risk being used as a subject for repeated assessment, the project group has considered it necessary to define risks such that they are mutually exclusive. In order to avoid overlap between the concepts of public health risk, animal welfare risk, and animal health risk, the project group has limited the concept of animal health risk to those instances when public health and animal welfare concepts do not apply.

The group understands that those that remain are those economic effects on society in the form of loss of animals, loss of wild fauna, reduction in production, loss of access to markets, eradication costs etc., that result from the introduction and transmission of serious infectious animal diseases, and introduction and dissemination of invading species, that are regulated by official legislation.

\section{Plant health risk}

An attempt has been made to base the definition of plant health risk upon the definition of 'pest risk assessment' in The International Plant Protection Convention (1996). This definition is related to the risk of potentially economic consequences as a result of introduction and dissemination of plant pests.

In the advice from The International Plant Protection Convention (1996), the following factors are provided as examples for assessment:

- Type of damage;

- Crop losses;

- Loss of export markets; 
- Increases in control costs;

- Effects on ongoing integrated pest management programmes;

- Environmental damage;

- Indirect damage caused by the capacity of a pest to act as a vector for other pests or diseases;

- Perceived social costs, such as unemployment.

\subsection{Fair practice considerations}

According to Article 1 of EU-Regulation 882/2004, there are two considerations that should be ensured by official control of the feed and food legislation, and also the animal health and animal welfare legislation. These are:

a. Preventing, eliminating or reducing to acceptable levels risks to humans and animals, either directly or through the environment; and

b. Guaranteeing fair practices in feed and food trade and protecting consumer interests, including feed and food labelling and other forms of consumer information.

Article 1, parts a and b, of EU-Regulation 882/2004 provides a distinction between risk and other considerations. The project group has interpreted EU-Regulation 882/2004, such that the considerations described in Article $1 \mathrm{~b}$ (considerations regarding fair practice and consumers) are not understood as risk-based priorities. However, the authorities must, on the basis of experience or requirements, prioritise and allocate resources to official control with considerations towards fair practices. A system for prioritising of resources to official control, with respect to legislation, will not be complete without all the considerations being included in the total assessment by some means.

The consumer considerations are associated with the consumers' rights to safe food and an adequate diet that meets nutritional requirements and preferences. The consumer considerations encompass, in addition to health, considerations concerning, amongst others, quality, fair practices, choice, culture, ethics, religion and environmentally-appropriate production.

The project group understands that official control of fair practices has become more and more important, whilst official control of quality, which previously was very important, has become less central because of improved self-regulation within the market.

For some, it makes sense to discuss risk associated with fair practices and quality. For others, this is incomprehensible. Should it be required, it can be possible to approach fair practices and quality problems as risk. For example: 
Fair practice risk: A reduction in possibilities for informed choice, because the consumers do not receive the information that they have a right to.

It is the opinion of the project group that the fair practice perspective is most relevant regarding assessment of the willingness and capability of an individual business to adhere to the legislation.

\subsection{Environmental considerations}

With respect to EU-Regulation 882/2004, the project has not defined any environmental risks. Those animal health and plant health risks that are defined also encompass the risk of damage to wild flora and fauna. The animal health and plant health administration does not differentiate between domesticated and non-domesticated animals and plants.

Should the control authorities wish to define other environmental risks (e.g. risks associated with diminishment of genetic resources, dissemination of viable GMOs to the environment etc.) within the model for riskbased official control, this should be possible. 


\section{Risk analysis and risk management}

A risk-based approach to health hazards associated with foods has been developed (FAO/WHO, 1995). This approach is called risk analysis. The concept apparatus is relatively complicated, and it is not made simpler by, for example, FAO/WHO (1995) and ISO/IEC (2002) using different contents in individual concepts. This is particularly applicable in the concepts 'risk analysis' and 'risk assessment'. With time the distinction between these concepts will become erased.

In 1995, FAO/WHO regarded risk analysis (FAO/WHO, 1995) as three functionally separate, but overlapping, tasks (risk assessment, risk management, risk communication). The framework has since been modernized. FAO/ WHO (2006-1) now regards risk assessment and risk management as two functionally separate tasks 'floating' in a sea of communication.

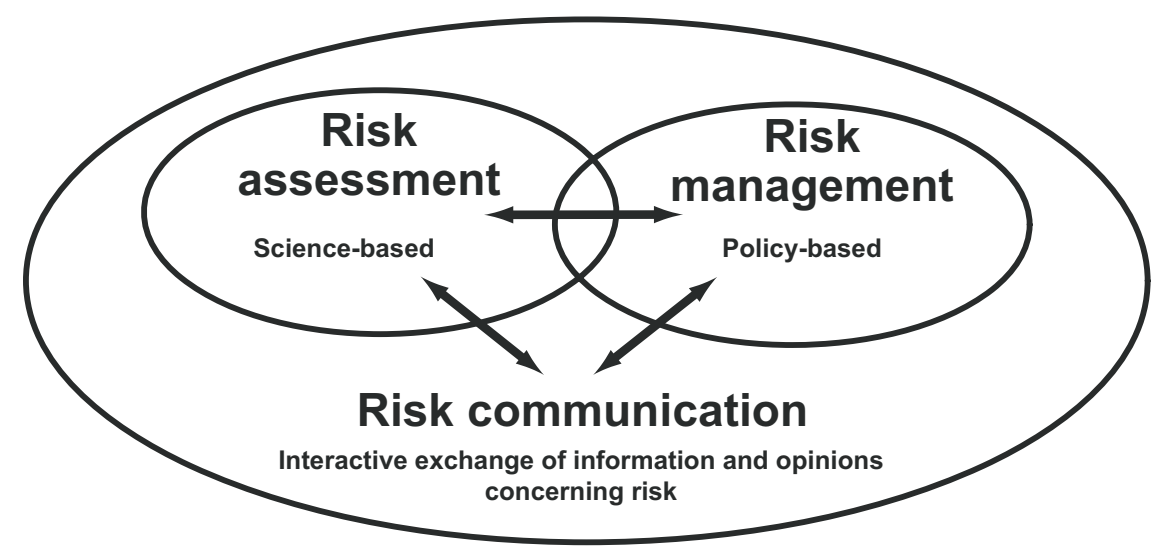

Figure 2. Risk analysis (cf. FAO/WHO)

In order to achieve a high level of protection of human life and health, the food legislation should be based on risk analysis, except when this is not appropriate due to circumstances or the nature of the measure. The risk assessment shall be based upon available scientific evidence and conducted in an independent, objective and transparent manner. Risk management will take into account the results of the risk assessment, especially opinions from the European Authority for Food Safety (EFSA), other factors relevant to the case under consideration, and the precautionary principle, when the circumstances for this are relevant (European Parliament and Council of The European Union, 2002) 
The risk analyses aspire to be objective analyses that describe how things actually are. The risk management aims to be subjective or normative analyses that relate how things ought to be. Value analyses form part of the risk management. Thus the risk analysis conducted forms an interface between documented knowledge and values.

\subsection{Risk management}

FAO/ WHO (2006-2) defines risk management as: "a process of weighing policy alternatives to accept, minimize or reduce assessed risks and to select and implement appropriate options."

HM Government Cabinet Office Strategy Unit (2002) points out that good risk handling is first and foremost a process that uses human judgement. It is people who will judge, make decisions, and act. Good tools, for example measurements, mathematics, data systems etc., can be of enormous benefit, but they cannot be substituted for the human act of judgement itself. The report points out that there is a danger that risk handling might be regarded as a mechanical process. This could be damaging and could potentially lead to the important issues being missed. The significance of human judgement in all forms of risk handling cannot be emphasised strongly enough.

For risk management, there have also developed been many concepts, illustrations and descriptions of the processes. In their description, FAO/WHO (2006-2) have called the first section of the process, preliminary activities. Following on from FAO/WHO (1997), this section of the process begins with the following steps:

- Identification of problem

- Establishment of a risk profile

- Ranking of the hazards for prioritisation of risk assessment and risk management.

It is these stages that the project group has attempted to implement through its model for risk-based official control.

\subsection{Risk-based or experience-based prioritisations}

Much of the food legislation was developed when there was limited knowledge or information about the association between the occurrence of hazards in food and the actual risk to which consumers were exposed. The management of food safety has often been directed towards reducing or eliminating the exposure to hazards, with the expectation that this reduces the risk. Currently, at the time of writing this report, discussion is in progress in the Codex alimentarius work group CX/GP on the use of 
the expression 'risk-based'. There exists, among others, a proposal that only standards that have been built upon scientific knowledge about those risks to which the consumer is actually exposed ought to be characterised as risk-based standards. This proposal demands a clearer understanding of the difference between the handling of hazards and risk management (FAO/WHO 2006-3).

The project group has not discussed 'risk-based standards' nor 'riskbased legislation', but has nevertheless been confronted by a similar question with respect to prioritising official control, namely: what is riskbased official control? The project group is of the opinion:

1. In some areas there appears to exist sufficient knowledge or information on the association between the occurrence of hazards and risk, combined with a strong possibility of estimating severity and incidence. In such instances it is possible to undertake risk-based prioritisation.

2. In other areas there is evidence that the hazards can have undesirable effects, but the reason or effective association between the hazard and the risk is so complex, or the estimation of the risk is so difficult, that it is not possible to conduct risk-based prioritisation. Instead, prioritisation must be undertaken on the basis of previous experience from handling the relevant hazards. We have chosen to designate such prioritisation as experience-based prioritisation.

\subsection{Risk profiles and ranking of hazards}

In the establishment of risk profiles and the ranking of hazards, it is customary to use a risk profile matrix. By using such matrices it is possible to chart the risks in relation to probability and consequence. In this approach it is possible, when it is appropriate, to combine qualitative judgements with quantitative analyses. Usually, the probabilities and consequences are defined as high, moderate/medium or low. This is a process with a high resource requirement. HM Government Cabinet Office Strategy Unit (2002) provides the following example of how this approach can be conducted: 


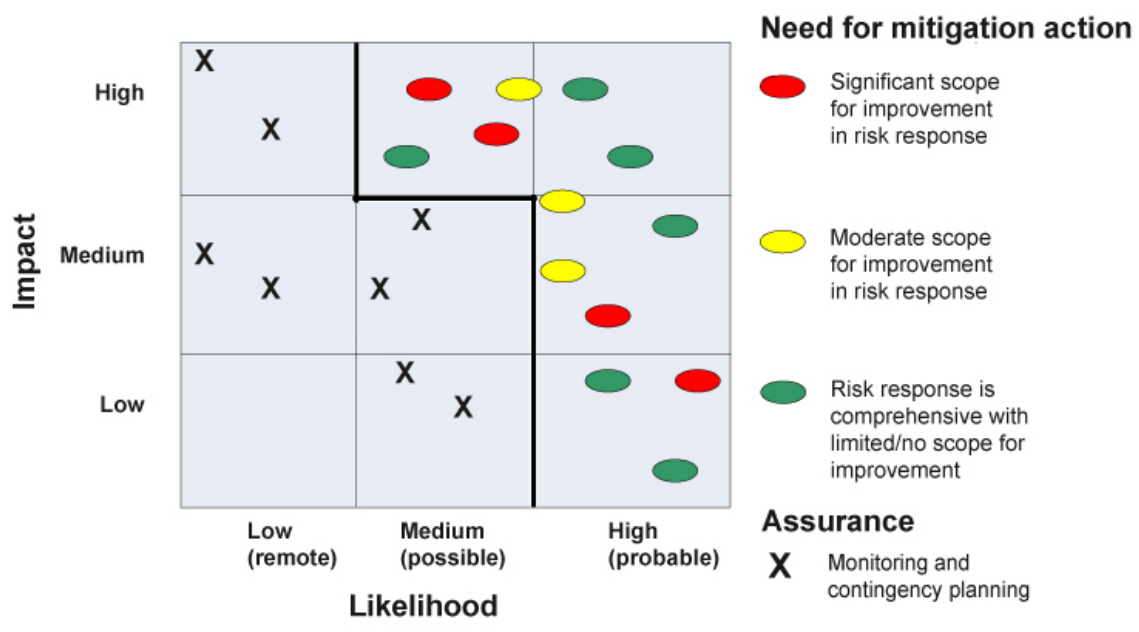

Figure 3. Risk profile matrix - the thick line denotes the risk tolerance.

The matrix is presented as an illustration to demonstrate those possibilities that arise in the use of such matrices. However, it can be politically difficult for the control authorities to operate with risk tolerances, as this model does.

In its risk-based approach to food safety, FAO (2003) has used as a basis that control resources should be directed towards those hazards that represent the greatest threat and towards those areas where the greatest risk reduction can be achieved in proportion to use of resources. The matrix contains both these elements.

Risk profile matrices can also be used as guides on how to approach different hazards:

- Hazards that lie in the upper right-hand section of the matrix are typical candidates for intensive official control.

- Hazards that lie in the lower left-hand section of the matrix are candidates for basic control.

Additionally:

- Hazards in the upper left-hand corner are typical candidates for contingency measures.

- Hazards in the lower right-hand corner are typical candidates for guidance measures.

- Hazards in the lower left-hand corner can also be prioritised for other reasons (e.g. political). 


\section{The Hazards}

Hazards are potential sources of harm. The project group has attempted to identify those types of hazard that are relevant to EU-Regulation $882 / 2004$. The group has, with a view to a crude analysis of hazards in the food chain (see chapter 8), attempted to:

- Define hazards at the overview level;

- Provide a degree of detail, so that all types of hazard are handled;

- Formulate hazards in such a manner that they mutually exclude each other, but together provide entire coverage.

The categorisation has been based upon the nature of the hazards, regardless of the size of the categories.

The project has identified the following hazard categories:

Table 1. The hazard categories

\begin{tabular}{|c|c|c|}
\hline & Hazard Categories & Possible causes of: \\
\hline 1 & Animal diseases & $\begin{array}{l}\text { Public health risk } \\
\text { Animal health risk } \\
\text { Animal welfare risk }\end{array}$ \\
\hline 2 & Plant pests & Plant health risk \\
\hline 3 & $\begin{array}{l}\text { Infectious agents (except those included in } \\
\text { categories } 1 \text { and } 2 \text { ) }\end{array}$ & $\begin{array}{l}\text { Public health risk } \\
\text { Animal welfare risk }\end{array}$ \\
\hline 4 & Chemical agents and physical elements & $\begin{array}{l}\text { Public health risk } \\
\text { Animal welfare risk }\end{array}$ \\
\hline 5 & Allergens & Public health risk \\
\hline 6 & Living genetically modified organisms (GMOs) & Public health risk \\
\hline 7 & Unacceptable keep and treatment of animals & Animal welfare risk \\
\hline
\end{tabular}

Comments on categories 1 and 3 in table 1 :

Infectious agents in hazard category 3 can also be causes of animal diseases. From a professional viewpoint it is almost impossible to differentiate between categories 1 and 3. However, we believe that the system for risk classification will be simpler if an attempt is made to differentiate, in a rational or practical manner, between those infectious agents which first and foremost are recognised and tackled as animal diseases, and those which are first and foremost treated as food-borne and feed-borne infectious agents. 
Comments on category 6 in table 1 :

There are certain to be different opinions regarding whether living GMOs should be regarded first and foremost as a problem with respect to fair practices, to the environment, or as a potential threat to public health. Savadori et al (2004) have conducted a study on the risk perception of both experts and the public associated with the use of biotechnology.

\subsection{More detailed description of the hazard categories}

\section{Animal diseases}

This category encompasses infection with serious, infectious animal diseases that are the basis for restrictions in the animal health legislation, including invasive species that must be regulated by animal health legislation. Descriptions of these animal diseases can be found in various places, including at website: http://www.oie.int/eng/maladies/en_alpha.htm

\section{Plant pests}

This category encompasses plant pests regulated by the European Council's directive 2000/29/EF (Council for the European Union, 2000) and possibly by communal or national plant health directives.

Descriptions of the hazards that represent a risk to plant health can be found at: https://www.ippc.int/IPP/En/default.jsp and https://www.ippc.int/ servlet/CDSServlet?status=ND0xMzU0NSY2PWVuJjMzPSomMzc9a29z

Infectious agents

(excluding those included in categories 1 and 2, in table 1)

This category encompasses:

- Infectious agents that can be transmitted from animals to people via food without them causing illness, or only a small degree of illness, in the animals (this includes transfer of resistance against antibiotics);

- Infectious agents of animal diseases, other than serious infectious diseases, transmitted via feed;

- Other infectious agents from humans or the environment that can occur in food and feed.

With a view to further analysis (see chapter 8), it is expedient to divide this hazard group further into sub-groups, for example:

- Bacteria, including toxin production and possible resistance problems;

- Viruses;

- Fungi, including toxin production; 
- Algae, including toxin production;

- Parasites.

\section{Chemical agents and physical elements}

The project group has found it appropriate to handle chemical and physical hazards as a single category. With a view to further analysis (see chapter 8), it is expedient to divide this hazard group further into subgroups, for example:

- Environmental toxins;

- Radioactivity;

- Process-derived contaminants;

- Pesticide residues;

- Pharmaceutical residues;

- Cleaning and disinfection product residues;

- Pollution and migration from materials;

- Illegal quantities of additives;

- Plant toxins;

- Illegal nutrients;

- Incorrect concentrations of nutrients;

- Residues and derivatives of GMOs (not living GMOs);

- Physical elements.

Descriptions of hazards that represent a risk to public health can be found at various places including www.foodrisk.org/index.cfm, www.who.int/ foodsafety/en and www.fao.org/ag/agn/jemra/index_en.stm.

\section{Allergens}

Allergens represent a risk. The risk, however, is different in nature to that from other chemical agents. The risk management of allergens is first and foremost in the form of marking and official control of marking regulations.

Living genetically modified organisms

Illegal living GMOs are considered a hazard category.

Unacceptable keep and treatment of animals

With respect to animal welfare, there is presently no international recognised hazard concept. The project group faced significant challenges in its efforts to define relevant hazards with respect to animal welfare.

The 1965 Brambell commission in England provided a comprehensive statement on the concept of animal welfare, and this has been summarised in the form of 'five freedoms' for domesticated animals for ideal welfare. 
- Freedom from thirst, hunger and malnutrition.

- Freedom from discomfort due to environment.

- Freedom from fear and distress.

- Freedom from pain, injury and disease.

- Freedom to express normal behaviour for the species.

(Wikipedia, 2006)

The project proposes to group the hazards with respect to the needs of animals as follows:

Unsuitable keep of animals:

- Unsuitable buildings and fittings/equipment;

- Poor protection of animals.

Unsuitable feeding:

- Inappropriate quantities of feed and water;

- Incorrect composition of feed ${ }^{3}$;

- Feed and water of poor quality ${ }^{3}$;

- Incorrect frequency of feeding with respect to the animal's requirements.

Poor treatment of animals:

- Inappropriate grouping of animals;

- Brutal or unethical handling and overloading of animals, including doping and mistreatment;

- Insufficient care, including treatment of illness

\subsection{Unfair practice}

Unfair practice can contribute towards risks to public health, animal health, animal welfare, and plant health, but it is always another hazard that is the direct cause of possible harm.

However, unfair practice can be a direct cause of: reduced possibilities for informed choice, because the consumers do not receive the information to which they have a right.

Thus a hazard approach should be used for this last point, and possible reasons for harm include the following:

- Omission of relevant information;

- Incorrect information;

- Misleading information.

\footnotetext{
${ }^{3}$ Other hazards than those included in categories 1,3 and 4 of table 1.
} 


\section{The Food Chain Approach}

FAO (2003) has developed a strategy for a food chain approach. The strategy is based upon all the participants, from the primary producers to the consumers, and also the authorities, working together and sharing the responsibility for safe products. The chain cannot be stronger than the weakest link.

This strategy works towards a more preventive and unified approach to risk. Integrated strategies to reduce the most serious risks throughout the chain should be included in the systems for food safety. The strategy can also be referred to as a "from farm or sea to the plate" approach.

The strategy assumes risk-based prioritisation. Control resources must be directed towards those hazards that represent the greatest threat. The hazards must be increasingly prevented, controlled and managed at the source.

Food safety systems that utilize a chain approach will also increasingly make use of analyses from outside sectors, so that the systems will be able to incorporate other risks associated with animals, plants, health, environment and other related conditions.

This report is based on such an approach. We have examined closely how the control authorities can use and implement these principles in relation to official control within the working area of EU-Regulation 882/2004. For this to be possible, a thorough description of the food chain has been necessary. Whilst there are many product-specific chains described in the literature, these have been too fragmented and detailed with respect to analysing risks and hazards across such a broad field as that embraced by EU-Regulation 882/2004.

We have therefore invested a degree of work in the development of a description of the food chain from farm to fork, as viewed from a more elevated level. The chain also includes products from the sea, and a number of vegetable and animal products that are not used for consumption. Whilst it does not completely cover everything, we have, for pedagogical reasons, chosen to use the recognised designation, 'the food chain'.

We have chosen to use as our basis, an illustration of the food chain from ISO standard 22000 (ISO 2005). This has been revised with the aim of making it applicable for use in analysing the occurrence of all the types of hazard that are covered in EU-Regulation 882/2004, not only foodrelated hazards. With respect to the illustration in ISO standard 22000, we have

- Deleted a column that shows the authority's role;

- Included a column that illustrates the environment's importance; 
- Further divided the primary link;

- Added a link to include the use of vegetable and animal products for other reasons than that of food;

- Made various minor modifications;

- Altered the specifications of some of the links.

It is emphasised that the model should be simple, and clearly set out. Several of the links could be further divided. In order not to complicate the model, the use of arrows is limited to the most important interactions. Therefore, amongst others, arrows have been excluded if they cross one or several links, for example when primary products go directly to wholesalers, shops or services.

The model that has been developed is presented on the following page. The illustration consists of three columns:

1. The chain (the central column) includes all those who work with production and trade of all types of plant products, animal products and foods.

2. The right-hand column includes all those who supply goods and services to the central chain. In order to maintain the simplicity of the model, it is practical to list all those businesses that can occur at many points throughout the chain in their own separate column. Because they are placed in this column, does not mean that these components are of lesser importance with respect to official control.

3. The left-hand column illustrates the environment. Hazard sources can also occur in the environment. 


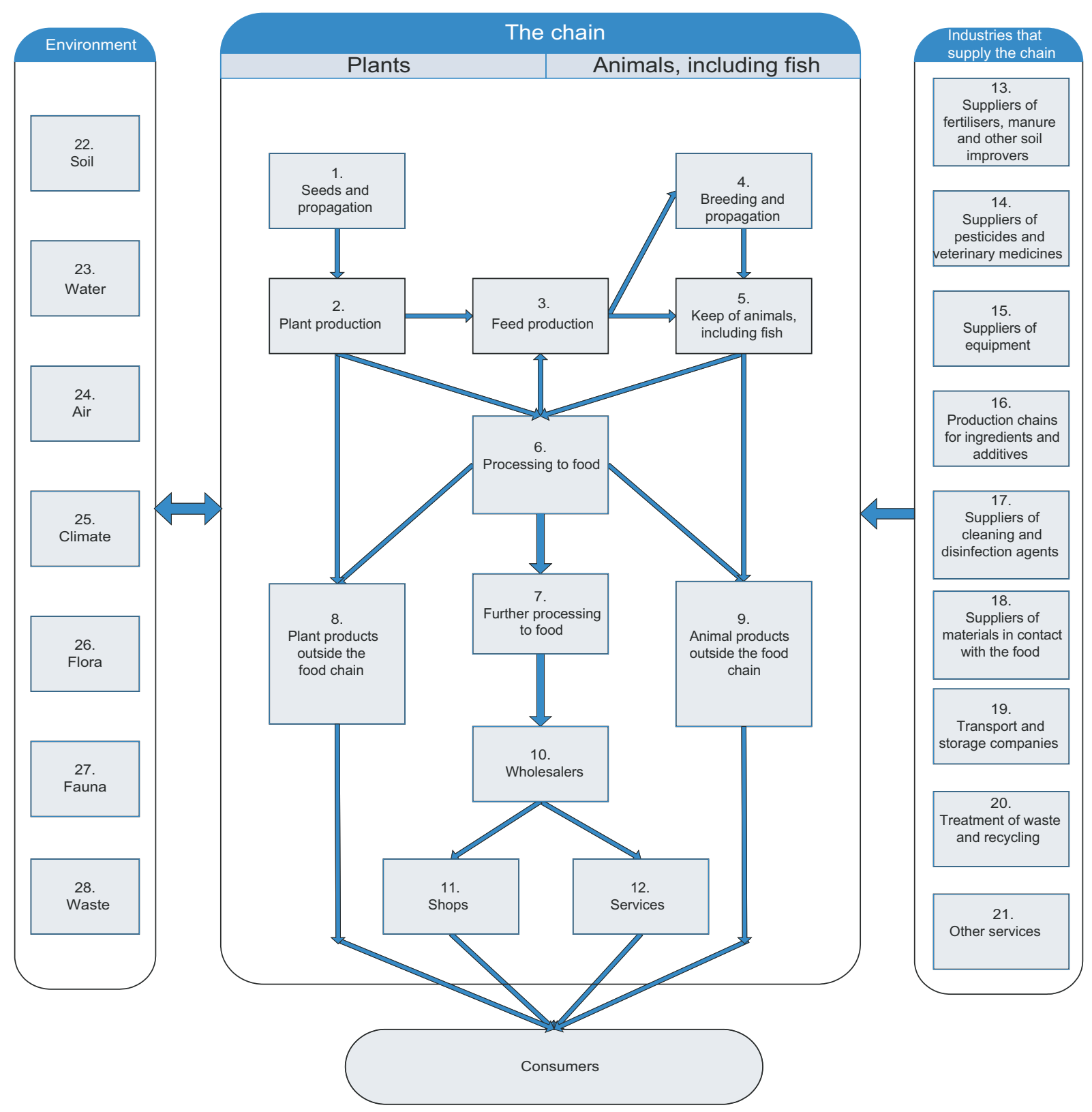

Figure 4. Illustration of the food chain

\subsection{Comprehensive description of the chain in the form of industries}

First and foremost, it is businesses that are the subjects of official control. The model for risk-based official control that is presented in the next chapter assumes that the food chain has been thoroughly described and divided into appropriate groups of businesses. An appropriate group is one that to some extent shares a similar delineation of risk, and there are 
limited differences in risk between the businesses within the group. Industries, sections of industries, or groups of industries can form an appropriate grouping system. Each business group should have, with consideration of implementation of the system, a unique and unambiguous identity.

The model also assumes that each and every business is assessed for its appropriateness in belonging to a particular group. Information on the assumed appropriateness of belonging to a particular group should be stored in a database on the business, and used for prioritisation of official controls. Databases should be organised such that individual data points can be aggregated to population data. Data on individual businesses must be accessible, at a minimum, at the operative level that executes the control.

The project group considers it appropriate to use the Standard Industrial Classification (Statistics Norway, 2003) to describe the links in the chain and identify the relevant industries. The Standard is based upon the international NACE rev 1.1, as we believe that it is appropriate to use a recognised international standard. This enables the best possible comparison of data with other authorities, both nationally and internationally. Furthermore, it spares the control authority the work of developing and maintaining its own systems for grouping of businesses. Nevertheless, it should be noted that at the time of writing the Standard Industrial Classification is being comprehensively revised.

In Appendix 1 are listed 171 industries that have been identified as being appropriate for inclusion in official control (cf. EU-Regulation 882/2004). In consideration of grouping the industries in relation to the food chain, some of these industries are divided further, so that the total number of industries and sub-groups is 195. Some of the industries are central to an individual control authority's task portfolio, whilst others are more peripheral. We recommend therefore that each individual control authority should assess which are relevant with respect to its own task portfolio, which can be omitted, which can be combined, and which should be split further, with a view to obtaining a more appropriate division for that individual authority. The project group has assumed that most authorities will have a limited capacity to assess every industry individually and therefore that if it is decided to conduct industry assessments (see chapter 9), it will be necessary to use a grouping system.

The list provided in Appendix 1 is a preliminary draft and may be incomplete in some areas. It should therefore be viewed critically. Nevertheless we hope that it is helpful and useful. If the list is not considered suitable or adequate, then links, industry groups and industries can be described as is found to be more appropriate. 


\subsection{Do import activities belong in the food chain?}

In many cases, import businesses can be decisive for the risk delineation associated with individual types of business. Import of goods is an activity that occurs in many different links in the chain. The project group regards import, where it is relevant, as an integral component of the activities of different industries and businesses.

Many private individuals who, in any other situation, would not be subjects for official control, also import goods. The food chain and the model for risk-based official control, as presented in the next chapter, does not take into consideration the requirement for official control of this type of import, nor does it concern itself with border control of animals, plants, food and feed, that have the character of product control. The control authorities must prioritise official control of this aspect separately.

Codex alimentarius (2006) has stipulated principles and guidelines for risk-based control of imported foods. Many of these principles seem as though they could be used by several types of import control.

\subsection{The food chain also includes the environment}

Hazards do not only exist in businesses and in products (cf. Chapter 5). In some instances, the official authorities may consider it most appropriate to channel their control resources towards monitoring and control of hazards in the environment.

The food chain approach uses as a basis, amongst others, the principle that hazards must be increasingly prevented, controlled and managed at the source. Inclusion of the environment in the chain enables analyses of hazards that also take into consideration their presence in the environment.

There is no further description of the environment column in the chain.

\subsection{The food chain does not include activities in the private home}

Hazards that can represent a threat to public health and animal welfare can also arise in a private home. Such threats have not been taken into consideration in the illustration of the food chain, nor in the model that is presented in the next chapter. 



\section{The model for risk-based official control}

The legislation is directed towards businesses, including individual persons. The main objective of official control is to ensure that these businesses, including individuals, comply with the regulations. These are the subjects of the chain discussed in the previous chapter.

It is collectively recognised that there is a requirement for a tool that can assist the authorities in conducting risk-based official control.

\subsection{Purposes and premises}

The purpose of risk classification of businesses is to:

- Rank businesses with respect to risk;

- Determine the focus of official control or supervision (where it is most important to have official control for a particular type of business).

Risk classification provides the degree of shading in the perception of a business, and strengthens the basis for the authority's decision on prioritisation of control efforts.

A prioritised control effort assumes that a number of premises are fulfilled (cf. EU-Regulation 882/2004):

- Objectives and strategies have been formulated;

- Control methods are documented (inspection, audit, verification, sampling and analysis, monitoring), as are the criteria for the control methods used;

- Control personnel are suitably and adequately qualified;

- The authority has sufficient resources (time/capital/technical resources) to conduct the control duty;

- The authority has a system for appropriate division of resources, (planning, conducting and following up the official control), at all levels of the organisation (local, regional and national). 


\subsection{Elements in the risk classification of businesses}

A step-wise process for risk classification of businesses has been proposed. This refers to the illustration of the model provided in the introduction. Here we give a brief description of the model. The steps in the model will be examined more thoroughly in the following three chapters.

\subsubsection{Survey for hazards in the food chain}

- All the main hazard groups and control points in the food chain shall be identified.

- Where official control of the different hazard groups is most important shall also be identified.

- A national analysis shall seldom be conducted; only when there have been large structural changes in the food chain or new hazard categories have been introduced. Nevertheless, the analyses must be continually maintained as new knowledge emerges through industry assessments.

\subsubsection{Industry assessment}

- Risk profiles and assessment of risks associated with appropriate business groups (industry groups or industries) shall be prepared.

- Industries shall be classified into one of 4 risk classes as follows:

1. Industries with considerable risk of undesirable incidents or situations;

2. Industries with moderate risk of undesirable incidents or situations;

3. Industries with low risk of undesirable incidents or situations;

4. Industries with negligible risk of undesirable incidents or situations.

- The focus of official control or supervision (where it is most important to have official control) for a particular industry will be described.

- Industry assessments are national assessments that shall be conducted regularly.

\subsubsection{Assessment of businesses}

The individual businesses shall be assessed separately. The risk associated with the business shall be assessed as high, normal or low in relation to the average for the industry to which the business belongs. Thus, a high risk means that an individual business is classified as having a higher risk than that determined for that particular industry. Similarly, a low risk means that an individual business is classified as having a lower 
risk than that determined for that particular industry. Businesses that encompass several industries shall be classified with respect to that industry which has been determined to have the highest risk classification.

Assessments of businesses are local assessments that shall be conducted continuously in association with official control.

\subsection{Implementation of results}

Risk classification is used to determine the extent of control for industries and individual businesses, in relation to the norms that the individual control authorities decide.

\subsection{Critical success factor}

The results must be maintained continuously and evaluated regularly.

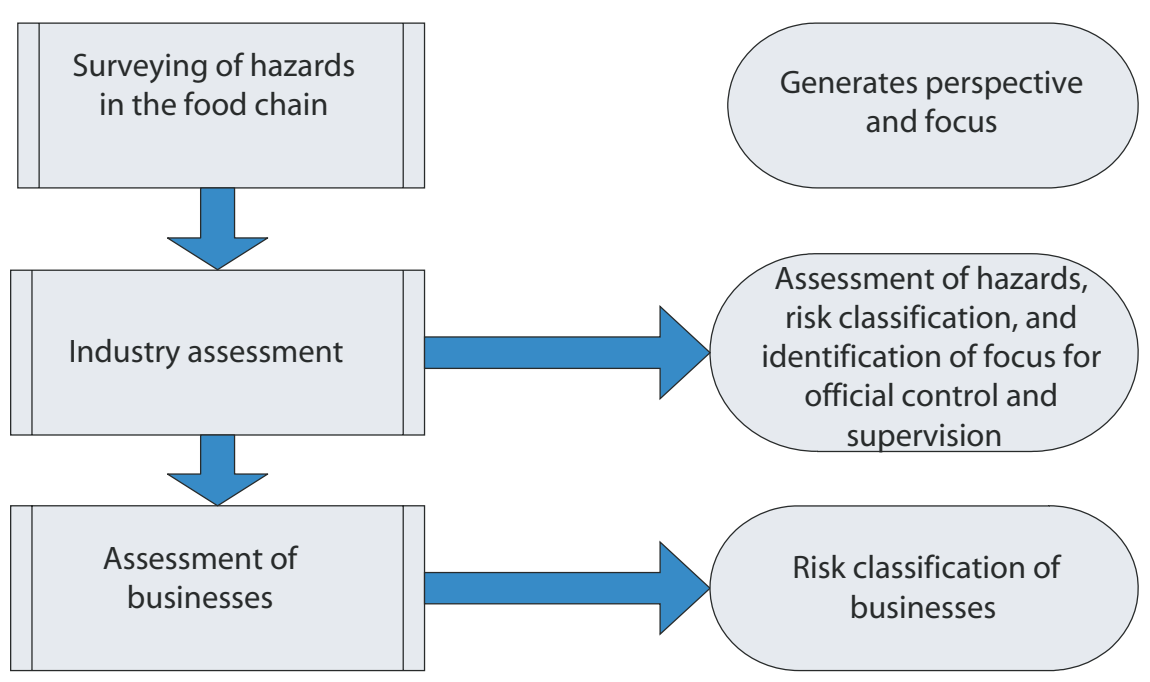

Figure 5: The elements in the project's model for risk classification 



\section{Survey of hazards in the food chain}

As the basis for risk classification of industries (Chapter 9), we recommend that an initial survey and analysis is conducted of the hazards that are important in leading to official control or supervision in the different links in the chain, and that this is correlated with the various industries. Such analyses do not need to be conducted often; only when there have been significant structural alterations in the chain, or new hazards have been introduced. Nevertheless, it is vital that these analyses are continually maintained, so that new knowledge or information is incorporated as it emerges through industry assessments (Chapter 9).

Through such an analysis the following should be achieved:

- Identification of how the different categories of hazard arise, and how they are distributed throughout the chain;

- Identification of which risks and hazard categories are relevant to particular links in the chain, and to which they are irrelevant;

- Creation of a framework for discussion and risk communication on where in the chain it would be most effective to direct the official control, supervision or intervention with respect to the various hazard categories;

- Direction of the focus towards those hazard categories where it is important to have control in particular links in the chain, together with identification of in which industries it is important to control these hazards.

With such an approach, in which the chain is appraised externally, it is easier to become aware of those risks which lie in the 'grey zones' between the links in the chain, and which would perhaps not have been detected by observing the industries individually.

Such an analysis does not provide information about the risks (the probability and consequence), but does identify where in the chain it can be most effective to use resources to control the actual hazards. The risks themselves are assessed more closely as links in the industry assessments (see Chapter 9). 


\subsection{Recommendation of the analytical process}

We have proposed here a systematic approach on how hazards in the food chain can be surveyed and analysed. The process that is recommended here is only one of several possible approaches for undertaking such analyses. We therefore recommend that users proceed tentatively, and conduct the analysis in such a way that the individual authorities perceive as optimal.

We recommend that the process be initiated at an overview level, with a basis in:

- The food chain (see Chapter 6);

- The various hazard categories (see Chapter 5).

During the process, it can be brought down to the more detailed levels as is appropriate.

\section{Associating hazard categories with links in the chain}

We recommend that the analysis be commenced by connecting the hazard categories (Chapter 5) with the various links in the chain (Chapter 6). The objective of this is, first and foremost, to create an overview and to simplify further analysis. Relating the hazard categories to the links in the chain can be performed very simply.

The hazard categories can be addressed one at a time, and for each one, it can be physically marked (using colour, crosses or rings) in the illustration of the food chain (figure 4), where the particular hazard categories can occur. The result will be very much an overview from a superior level and will contain many obvious features. However, it is now very simple to remove systematically those points of minimal relevance, detect the 'grey zones' and put into focus those aspects which are important.

\section{Specification of the hazards}

In order to analyse the probability further, it is necessary to specify the hazards more precisely than can be accomplished by using the broad main categories that are provided in Chapter 5 . It is therefore recommended that the hazard categories be broken down into sub-groups that reflect the required level of detail of analysis. The challenge here is to choose a level of detail that:

- Makes the analysis meaningful, but

- Is not so detailed that the analysis becomes unwieldy. 
In those instances where the hazards are treated in the form of groups, this type of analysis is particularly applicable, as the possibility of using too much detail is limited. Individual hazards can be assessed more closely as part of the industry assessment (see Chapter 9). Some hazard categories have been divided into sub-groups in Chapter 6, but for other hazard groups, definition of appropriate sub-groups is more difficult.

\section{Specification of the industry groups or industries}

This refers to Chapter 7, concerning a more detailed description of the chain in the form of industries. We believe that it is appropriate to survey and analyse hazards associated with the same industry groups or industries, as would be done for industry assessments (Chapter 9).

We therefore recommend that appropriate industry groups or industries be defined, with a view both to surveying and analysing hazards (this chapter), and to conducting industry assessments (Chapter 9). Again it is advisable not to include too much detail here, in order to avoid the further analysis and industry assessments becoming too unwieldy (cf. Chapter 9).

Identification of where the hazards should be controlled in the chain

We recommend that the sub-groups of the hazards are initially analysed one at a time, and the following points identified:

- Critical links in the chain with respect to being able to reduce a particular risk;

- Links in the chain where a particular risk should be monitored and where measures should be considered for reducing the risk;

- Links in the chain where it is less pertinent to expend resources on reducing the risk.

For such analyses it can be practical to use matrices, e.g. as illustrated below:

Table 2: Survey of where hazards should be controlled in the food chain.

\begin{tabular}{|c|c|c|c|c|c|c|c|}
\hline \multirow[b]{2}{*}{ Hazard group } & \multicolumn{2}{|c|}{ Link in the food chain } & \multirow[b]{2}{*}{$\begin{array}{l}\text { Feed } \\
\text { production }\end{array}$} & \multirow[b]{2}{*}{$\begin{array}{l}\text { Breeding and } \\
\text { propagation of } \\
\text { animals }\end{array}$} & \multirow[b]{2}{*}{$\begin{array}{l}\text { Keep of } \\
\text { animals }\end{array}$} & \multirow[b]{2}{*}{$\begin{array}{l}\text { Processing } \\
\text { to food }\end{array}$} & \multirow[b]{2}{*}{ Etc } \\
\hline & $\begin{array}{l}\text { Seeds and } \\
\text { propagation }\end{array}$ & $\begin{array}{l}\text { Plant } \\
\text { production }\end{array}$ & & & & & \\
\hline Environmental toxins & & $x$ & $x$ & & $x$ & & \\
\hline Radioactivity & & $x$ & $x$ & & $x$ & & \\
\hline $\begin{array}{l}\text { Process-derived } \\
\text { contamination }\end{array}$ & & & $x$ & & & $x$ & \\
\hline Pesticide residues & & $x$ & & & & & \\
\hline Etc & & & & & & & \\
\hline
\end{tabular}


It is recommended that such a matrix is used for each hazard category, using crosses in the individual cells to indicate where official control would be relevant for one of the individual hazard sub-groups.

The requirement for official control of the various sub-groups of the hazards can be usefully described by using different colours for the crosses in the cells of the matrix, as follows:

- Red: Indicates that this is a link in the chain where official control of that particular sub-group of hazards is most important.

- Yellow: Indicates that this is a link in the chain where reliable official control or monitoring of that particular sub-group of hazards should be considered.

- Green: Indicates that this is a link in the chain where that particular sub-group of hazards might exist, but where official control of that hazard group is less relevant.

For example, process-derived contamination will be a suitable candidate for a red cross in the link 'further processing of food'. Other control points should perhaps be given a yellow or green cross.

In some circumstances, the appropriate control points will be obvious. In other cases, it will be less clear-cut where priority should be given to control a particular hazard group, and discussion about such instances could be profitable.

\section{Associating hazard groups with industries}

When the sub-groups of hazard have been connected with the appropriate links in the chain, the remaining task is to associate the hazard sub-groups with particular industries or industry groups (cf. previous section above, "Specification of the industry groups or industries").

For each industry group, relevant hazard groups should be identified. For each hazard group, an assessment should be made of which industry groups are relevant.

- Red: An important control point for a particular group of hazards;

- Yellow: A point in the chain where there can be a certain requirement for official control or monitoring of that particular sub-group of hazards;

- Green: A less important control point for particular group of hazards.

Similarly, regarding the problem of fair practices, a survey can be conducted of where responsibility for marking and information lies, and where it would be most effective for official control or supervision of these aspects with respect to this legislation.

N.B.: Assessment of whether or not an industry group or an industry is an important control point for a hazard group, does not involve assessing 
the probability or severity of the actual hazard. This is assessed during the industry assessment (cf. Chapter 9).

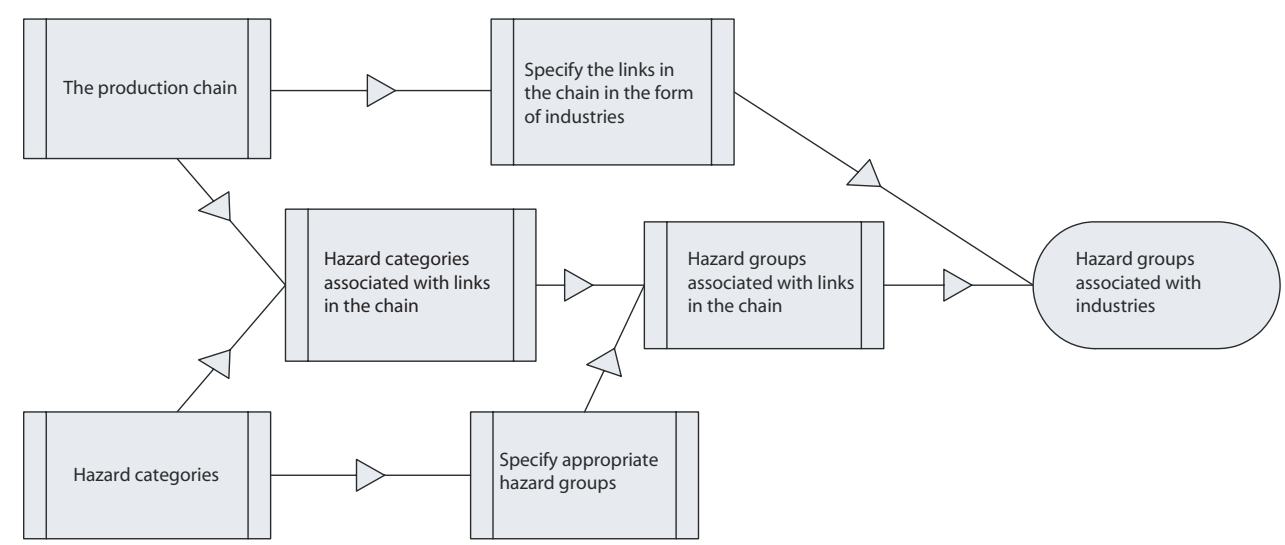

Figure 6: Survey of hazards in the food chain 



\section{Industry assessments}

\subsection{The requirement for assessments is variable}

The Nordic countries have organised the official controls that shall be conducted in accordance with EU-Regulation 882/2004 in different ways. As a result of this, the challenges of risk classification vary between the various different authorities involved.

For those control authorities that operate controls over a broad spectrum of businesses, it can be appropriate to conduct analyses of risks associated with industries or industry groups. This will be useful with a view to enabling an annual, cruder prioritisation of resource use. The same applies to those control authorities at a national level, with responsibility for ensuring equivalent control of regional and local units. The project group is convinced that within every industry there will be both businesses with a significantly higher risk than the group average, and businesses with a significantly lower risk than the group average. Nevertheless the risk level associated with individual businesses should be assessed in the form of a business assessment (see Chapter 10).

For those control authorities that operate supervisory regulation or official control in a more limited area, the requirement for analysis of risks associated with different industries or industry groups will be less. If there is a general consensus on the importance or significance of the different risks and hazards in a particular industry, then it might be pertinent to omit the industry assessments and concentrate on assessments of individual businesses.

\subsection{Proposal on the process for industry assessment}

It is proposed that the process for industry assessment should be composed of 4 steps, as follows:

1. Identification of risks and hazards associated with the industry;

2. Development of risk profiles for the industry;

3. Classification of the risk for the industry;

4. Determination of the focus of official control or supervision for the industry. 


\subsection{Identification of risks and hazards associated with the industry}

Provided that a survey of the hazards in the food chain has been conducted (Chapter 8), then this can be used as a basis for the industry assessment that will include:

- An identification of relevant risks;

- An identification of relevant categories or groups of hazards;

- An assessment on whether that particular industry is an important control point or not for individual groups of hazards.

It therefore remains to specify the relevant hazards for a particular industry. In order to maintain focus and to avoid such industry assessments becoming too all encompassing, time should be used, first and foremost, to identify hazards belonging to groups that have previously been identified as being relevant for that particular industry. The hazard groups identified as important control points should be given the most attention.

Additionally, it is obviously important to be aware that there can be hazard groups that in the previous analysis have not been connected to that industry. Only in exceptional cases should any significant time be spent on assessing such hazards. Similarly, minimal time should be expended on documenting assessments concerning the more peripheral or hypothetical hazard groups. However, if it is concluded that there have been some omissions in the previous survey of hazards in the food chain, then it is proper and important that this analysis is up-dated and corrected.

\subsection{Development of risk profiles for industries}

The project group proposes that risk profiles should be prepared with the help of risk profile matrices (previously discussed in Chapter 4), which provide a visual oversight together with a very broad or crude classification of the individual risks. Such risk profiles can give a reliable indication of combined risk. The project recommends the use of simple 3 by 3 matrices, as illustrated below: 


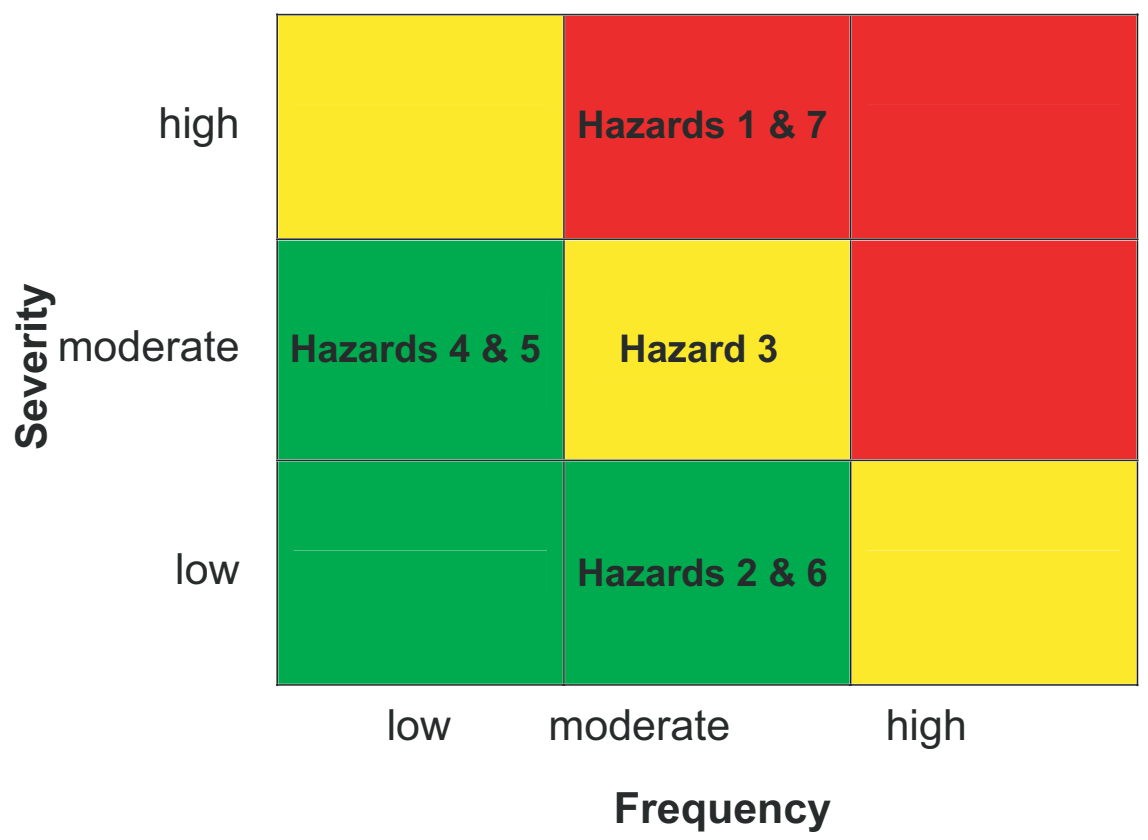

Figure 7: Example of a risk profile matrix.

It may be necessary to prepare up to 5 such profiles per industry (2 for public health risk, 1 for animal health risk, 1 for animal welfare risk and 1 for plant health risk).

- Red indicates critical risks that should be particularly prioritised for official control;

- Yellow indicates considerable risks that should also be objects of official control;

- Green indicates risks that should be given lower priority for riskbased official control.

Should it have been possible to assess all the hazards in the same matrix, this would have been simplest. However, the various risks (public health risk, animal welfare risk, animal health risk, plant health risk, any other potential risks) represent underlying values that are not comparable with each other. It is important to avoid trying to make comparisons between "apples and bananas". The project therefore proposes that the different risks be assessed separately in their own individual risk profiles. This will result in improved transparency and documentation of the professional assessments that are conducted during the process.

The project group had originally considered that there would be a requirement for four risk profile matrices (one each for public health risk, animal welfare risk, animal health risk and plant health risk). However, during the course of the project it was realised that two matrices are required for estimating public health risk, as follows: 
- One matrix for hazards which manifest themselves over a short period and where there is a direct connection between the hazard and the effect.

- One matrix for hazards where the undesirable effects manifest themselves first and foremost as long term effects, and where the connection between the hazard and the effect is less obvious.

It is proposed that for those industries where it is relevant, up to five risk profiles are developed for the following risks:

- Public health risk associated with biological hazards etc. (hazard categories 1 and 3; cf. Chapter 5);

- Public health risk associated with chemical agents etc. (hazard category 4; cf. Chapter 5);

- Animal health risk;

- Animal welfare risk;

- Plant health risk.

It is not recommended that there should be separate matrices prepared for public health risks associated with allergens, living GMOs and physical hazards. Where empirical data on the health effects of allergens exist, these should be treated in the model in the same way, and in the same matrix, as biological hazards to public health. If satisfactory empirical data on allergens is not available, the alternative is to treat allergens in the same way, and in the same matrix, as chemical hazards.

Furthermore, it is recommended that physical hazards and living GMOs be treated in the same way, and in the same matrix, as chemical hazards. The latter implies that prioritisation of official control of these hazard groups is based on experience of compliance with the legislation.

\subsection{Recommendations on assessment criteria}

Prioritisation of official control (cf. discussion in Chapter 4) can be based on both:

- Empirical data on risk

- Experience

\section{Risk-based prioritisations}

The best expression of risk is obtained from empirical data on how often undesirable events occur, and the severity of the effects of such events when they happen. With respect to biological hazards to public health, hazards to animal health, and hazards to plant health, there is a wealth of empirical data that can be used as a basis. 
External data available as a basis has often been obtained in another context, and in many cases can be difficult to utilise. The project recommends that the authorities in Nordic countries should use independent national institutes to assess the severity of risks and acquire data on the frequency of undesirable events. In the notes to ISO/FDIS 22000 (ISO, 2005) death registers, hospital admissions and sickness absences etc. are suggested as methods to determine the grade of severity of healthdamaging effects.

\section{Experience-based prioritisations}

Estimates of risk assume that there is a clear association between cause and effect. However, in some instances the connection between hazards and effects is ambiguous. With respect to chemical agents, we know that exposure over time represents a risk to public health, but we have limited knowledge on the effects of individual exposures. Similarly, we have limited information on how different events may affect animal welfare, how much suffering different events cause, etc. In the absence of empirical data on effects, then experience from the official control may be the best basis available on which to prioritise resource use. It might be objected that it is a circular argument to use results from official control as an expression of risk. However, in the absence of sufficient empirical data, it is necessary to base priorities on the best available information.

\section{Assessment criteria are defined by the_scales used}

How risk and experience are assessed has a decisive influence on how different hazards are assessed and ranked. Good scales for defining probability (e.g. frequency or incidence) and consequences (e.g. result or severity) are essential to enable an accurate ranking of hazards. Development of suitable scales for describing probability and consequence has perhaps been the most difficult assignment in the execution of this project.

Risk profiles for public health risks caused by biological hazards

Assumptions:

1. Lists of cases of reportable human illnesses reflect an authoritative, medically scientific risk assessment that can be applied directly.

2. The number of registered human illnesses related to food is well documented in most Scandinavian countries.

Assessment :

There exists a basis for conducting risk-based prioritisations. 
Recommendation:

The project group recommends that the following scales should be used for severity and incidence in risk profile matrices for public health risks caused by hazard categories 1 and 3 (cf. Table 1 in Chapter 5).

Table 3. Severity scale and incidence scale in a risk profile matrix for public health risks caused by biological hazards (excluding GMOs).

\begin{tabular}{|c|c|c|}
\hline & Severity & Incidence \\
\hline High & $\begin{array}{l}\text { Undesirable health effects in people caused by } \\
\text { pathogenic organisms in food, or from animals, } \\
\text { that } \\
\text { - } \quad \text { are covered by compulsory reporting } \\
\text { - } \quad \text { are either fatal or involve sustained adver- } \\
\text { se effects on an individual's health }\end{array}$ & $\begin{array}{l}\text { Annual incidence of } \geq 20 \text { registered } \\
\text { human cases per } 100,000 \text { of } \\
\text { population }\end{array}$ \\
\hline Moderate & $\begin{array}{l}\text { Undesirable health effects in people caused by } \\
\text { pathogenic organisms in food, or from animals, } \\
\text { that } \\
\text { - } \quad \text { are covered by compulsory reporting } \\
\text { involve transitory adverse effects on an } \\
\text { individual's health }\end{array}$ & $\begin{array}{l}\text { Annual incidence of } 2-20 \text { registe- } \\
\text { red human cases per } 100,000 \text { of } \\
\text { population }\end{array}$ \\
\hline Low & $\begin{array}{l}\text { Undesirable health effects in people caused by } \\
\text { pathogenic organisms in food or from animals, } \\
\text { that } \\
\text { - are not covered by compulsory reporting }\end{array}$ & $\begin{array}{l}\text { Annual incidence of } \leq 2 \text { registered } \\
\text { human cases per } 100,000 \text { of } \\
\text { population }\end{array}$ \\
\hline
\end{tabular}

Risk profiles for public health risks associated with chemical hazards

Assumptions:

Chemical agents in food and feed are possible causes of health risks. Threshold values are stipulated on the basis of scientific risk assessment of individual agents and their interactions with food and other agents. For agents without threshold values (typically process-derived agents or environmental contaminants), the European legislation provides the authority to conduct a specific risk assessment. When a specific risk assessment demonstrates that a food product contains an unacceptable health risk, then that food product becomes prohibited by law.

The legislation associated with chemical agents in feed and food is based on a combination of both risk assessments and the ALARP (as low as reasonably practicable) principle. The legislation, and compliance with this, reduces risk and engenders security. However, the empirical data available on the health effects of contravention of the legislation is limited.

\section{Assessment:}

A basis for conducting risk-based prioritisation does not exist. Instead, experience-based prioritisations should be conducted. These are based on the degree of compliance with the legislation.

When it has been ascertained that a business that produces or sells food is not satisfying the demands of the legislation, the control authority 
must apply the sanctions necessary to achieve compliance with the legislation. The sanctions must be effective, without being unnecessarily drastic. Therefore the sanctions applied must be dependent to some degree on the willingness of the business to alter its behaviour. The sanctions applied should also demonstrate, all else being equal, the healthrelated severity of the transgressions. However, the use of sanctions as an indication of severity assumes that good guidelines are in place so that the sanctions can be applied uniformly.

Recommendations on scales:

The project group recommends that the following scales should be used for severity and incidence in risk profile matrices for public health risks caused by hazard categories 4, 5 and 6 (cf. Table 1 in Chapter 5).

Table 4. Severity scale and incidence scale in a risk profile matrix for public health risks caused by chemical hazards etc.

\begin{tabular}{lll}
\hline & Severity & Incidence \\
\hline High & $\begin{array}{l}\text { The result of official control results in the } \\
\text { control authority requesting police investi- } \\
\text { gation of the business responsible, or } \\
\text { temporary closure of the business. }\end{array}$ & $\begin{array}{l}\text { Finds over threshold values occur } \\
\text { frequently. Proportion of controls* with } \\
\text { finds exceeds 10\% }\end{array}$ \\
Moderate & $\begin{array}{l}\text { The result of official control results in the } \\
\text { control authority making administrative } \\
\text { settlements, such as the issue of a fine or } \\
\text { order. }\end{array}$ & $\begin{array}{l}\text { Finds over threshold values occur } \\
\text { occasionally. Proportion of controls* } \\
\text { with finds is between } 1 \text { and } 10 \%\end{array}$ \\
& $\begin{array}{l}\text { The result of official control results in the } \\
\text { control authority highlighting only require- } \\
\text { ments for observance of rules, or making } \\
\text { no comment. }\end{array}$ & $\begin{array}{l}\text { Finds over threshold values seldom } \\
\text { occur. Proportion of controls* with finds } \\
\text { is below } 1 \%\end{array}$ \\
\hline
\end{tabular}

* For official control, a demonstration of contravention of the legislation is regarded as a find. In monitoring, a positive sample is regarded as a find.

\section{Risk profiles for animal and plant health risks}

\section{Assumptions}

The most important sources of information on the severity of animal and plant diseases are the risk assessments and recommendations from The World Organisation for Animal Health and The European and Mediterranean Plant Protection Organization, national risk assessments, and selfassessments, for cases where assessments/recommendations with more authority do not exist. The most important sources of information on the incidences and prevalences of animal and plant diseases are data from monitoring programmes, previous official control and international notification systems.

\section{Assessment}

There is a basis for conducting risk-based prioritisations. The project group recommends active use of national research institutes for assessment and ranking of hazards. 


\section{Recommendations on scales}

The project group recommends that the following scales should be used for severity and incidence in risk profile matrices for both animal health risks and plant health risks.

Table 5. Severity scale and incidence scale in a risk profile matrix for animal and plant health risks.

\begin{tabular}{|c|c|c|}
\hline & Severity & Incidence \\
\hline High & $\begin{array}{l}\text { - The disease/pest is not known to exist in the } \\
\text { country, or extensive precautions have been } \\
\text { implemented to eliminate an introduction or } \\
\text { limit its occurrence, and } \\
\text { The disease/pest has a significant potential } \\
\text { to become established in the country and is } \\
\text { expected to be very difficult/expensive to } \\
\text { eliminate if it does become established, and } \\
\text { If the disease/pest does become established } \\
\text { it would be expected to result in substantial } \\
\text { economic losses }{ }^{1}, \text { or represent a threat of } \\
\text { extinction to an endangered species }\end{array}$ & $\begin{array}{l}\text { The disease/pest is considered } \\
\text { to exist in the country, or new } \\
\text { outbreaks }{ }^{2} \text { of the disease/pest } \\
\text { occur at least annually. }\end{array}$ \\
\hline Moderate & $\begin{array}{l}\text { The disease/pest is not known to exist in the } \\
\text { country or extensive precautions have been } \\
\text { implemented to eliminate an introduction or } \\
\text { limit its occurrence, and } \\
\text { If precautions are not implemented the } \\
\text { disease/pest could result in substantial eco- } \\
\text { nomic losses }{ }^{1} \text { and } \\
\text { It is possible to maintain infection safe- } \\
\text { guards through trade or other effective mea- } \\
\text { sures. }\end{array}$ & $\begin{array}{l}\text { The disease/pest occurs occa- } \\
\text { sionally in the country. New } \\
\text { outbreaks }{ }^{2} \text { occur between } \\
\text { annually and every } 10 \text { years. }\end{array}$ \\
\hline Low & $\begin{array}{l}\text { - The disease/pest has limited potential for } \\
\text { becoming established in the country or is } \\
\text { believed to be of minimal economic signifi- } \\
\text { cance, or } \\
\text { The disease/pest is so widespread and } \\
\text { common that it is difficult to combat it effec- } \\
\text { tively. }\end{array}$ & $\begin{array}{l}\text { The disease/pest is not known } \\
\text { to exist in the country, and is } \\
\text { considered to be under good } \\
\text { control in countries exporting } \\
\text { relevant host animals/host } \\
\text { plants/products in which it may } \\
\text { occur. New outbreaks }{ }^{2} \text { occur } \\
\text { less than every } 10 \text { years. }\end{array}$ \\
\hline
\end{tabular}

Risk profiles for animal welfare risks

Analysis

Because of the lack of knowledge on the cause and effect association between hazards and risks in this field, the project group recommends an experience-based approach to risks to animal welfare, based on compliance with the relevant legislation.

Recommendations on scales

The project group recommends that the following scales should be used for severity and incidence in risk profile matrices for animal welfare. 
Table 6. Severity scale and incidence scale in a risk profile matrix for animal welfare risks.

\begin{tabular}{|c|c|c|}
\hline & Severity & Incidence \\
\hline High & $\begin{array}{l}\text { Serious contravention of laws and regula- } \\
\text { tions. Settled by investigation of busi- } \\
\text { ness/halt of activities/prosecution under } \\
\text { criminal law. }\end{array}$ & $\begin{array}{l}\text { Contravention of legislation occurs } \\
\text { often. The proportion of controls* } \\
\text { demonstrating contravention of } \\
\text { legislation exceeds } 10 \% \text {. }\end{array}$ \\
\hline Moderate & $\begin{array}{l}\text { Less serious contravention of laws and } \\
\text { regulations. Settled by injunctions, penal- } \\
\text { ties or fines. }\end{array}$ & $\begin{array}{l}\text { Contravention of legislation occurs } \\
\text { occasionally. The proportion of } \\
\text { controls* demonstrating contraven- } \\
\text { tion of legislation is between } 1 \text { and } \\
10 \%\end{array}$ \\
\hline Low & $\begin{array}{l}\text { Negligible contravention of laws and regu- } \\
\text { lations. Can be settled by adoption of } \\
\text { resolutions }\end{array}$ & $\begin{array}{l}\text { Contravention of legislation seldom } \\
\text { occurs. The proportion of controls* } \\
\text { demonstrating contravention of } \\
\text { legislation is less than } 1 \% \text {. }\end{array}$ \\
\hline
\end{tabular}

* A visit can be considered a control.

The matrix is equivalent to the risk profile matrix for public health risk caused by chemical agents.

\section{Assessment criteria concerned with fair practices}

The project group proposes an experienced-based approach regarding prioritisation of resources to official control concerning fair practices. The matrix developed for animal welfare risks can also be used for assessments of problems associated with fair practices.

\subsection{Critical success factors for development of risk profiles}

The project group has identified the following critical success factors for development of risk profiles:

- A dynamic system that incorporates changes and alterations;

- Good and readily accessible databases on incidence and severity;

- Engaging appropriate competence with respect to individual analyses;

- Time and resources available for the required number of analyses and the selected amount of detail;

- Internal and external risk communication of the results.

\section{A dynamic system that incorporates changes and alterations}

Static systems are vulnerable and can defeat their own intentions when large changes or alterations occur. Therefore it is important that the system should be: 
- able to incorporate structural alterations in industries and changes in production methods;

- able to incorporate changes in legislation compliance;

- dynamic, to enable updating of assessments when changes and alterations occur;

- such that regular checks of previous assessments are possible.

\section{Good and easily accessible database}

The quality of risk management is totally dependent on the quality of the knowledge and information used. With respect to biological hazards to public health, hazards to animal health, and hazards to plant health, there is a considerable amount of empirical data available. External data available to build upon has often been obtained in another context, and in many cases can be difficult to utilise. The project recommends that the authorities in Nordic countries should use independent national institutes to assess the severity of risks and acquire data on the frequency of these types of hazard.

As a basis for development of risk profiles for industries, several different sorts of information need to be acquired, e.g.:

- Information and knowledge on the hazards and risk conditions in the particular chain;

- Scientific information on the hazards and assessments of risk;

- Experience-based knowledge of the particular industry (internal control reports and other information accrued on the actual type of business);

- Other relevant knowledge or information on the industries (structural alterations, new technologies etc) that may affect risk, so that all possible angles of importance are addressed.

Whilst developing such risk profiles, the data must be used with discernment. It is important to be able to recognise features of development over time, not just chance fluctuations from year to year. Changes or alterations in the community that may influence hazard frequency should also be assessed, so that only viewing risks from a historical perspective is avoided. Additionally, consideration must be given to knowledge and information on under-reporting.

Both from transparency considerations, and to facilitate the updating and revision of the analysis by others at a later date, risk profiles should contain information on the background material used and about those assessments that have been conducted during the process. 


\section{Engagement of appropriate competence}

It is not possible to be objective about risk. Assessments of risk are always influenced by individual values and thought processes, and different people have different perceptions of risk. Therefore it is important that this work is not conducted alone, but that people with different professional approaches are involved, as well as different kinds of people.

It is important that industry assessments are done seriously and robustly enough that they are treated as being sufficiently authoritative. The assessments should not be too crude, and in some areas it can be important to acquire and utilise data from independent national institutes. Involvement of the industries themselves will also produce a better result and industry organisations that are invited to contribute are likely to cooperate more actively in the work to reduce the risks associated to their own industries.

\subsection{Risk classification of industry}

The risk profiles rank the hazards with respect to the various risks. Together these provide a certain indication of a combined risk. However, the risks that are handled in different matrices cannot be compared. With a view to decisions on prioritisation and allocation of resources, a form of total assessment of the industry should also be conducted. It is with respect to this that it should be emphasised again that the risk management process is primarily a value-based process. Official controls, with respect to EU-Regulation 882/2004, will involve prioritisations being made between different, not even comparable, risks, based on political guidance at any particular time.

It is proposed that approximate total assessments of the individual industries are conducted with a view to classification of the individual industries into one of four risk classes as follows:

1. Industries with significant risk of undesirable incidents or situations;

2. Industries with moderate risk of undesirable incidents or situations;

3. Industries with low risk of undesirable incidents or situations;

4. Industries with negligible risk of undesirable incidents or situations;

The qualitative assessments recommended can represent a contribution to improved risk communication and a proper risk culture. Such assessments will also be more flexible when it is necessary to take into consideration any prevailing political priorities at any given time.

Quantitative estimation of the risk classes is advised against, as all numerical measures of risk will represent extremely crude simplifications of reality. Additionally, considerable uncertainty will be associated with much of the information that would be used in the process. Mathematical 
estimations of risk level based on such crude and unreliable numerical data is considered to be of very limited worth. Also, by giving assessments of uncertainty and value an impression of objectivity, such mathematical assessments can work against their own intentions.

With respect to total assessments, the project group recommends that emphasis is laid upon the following points:

- The highest identified risk in the matrix (the weakest link) should be assigned significant importance;

- High diversification in the perceived risk can be indicative of a higher risk classification;

- Industries that have been identified as particularly effective control points with respect to significant risks, should have a high risk classification;

- Problematic tracking systems are indicative of higher risk classification. 


\section{Assessments of businesses}

Risk profiles for industries provide a certain overview. However, the risk delineation varies from business to business. For individual businesses, local knowledge is essential.

The assessment of businesses described in this chapter will be that which is encompassed by control of an individual business.

It is assumed that before a business assessment is conducted, an industry assessment of the relevant industry has been completed. This constitutes a starting point for the assessment of the business. During the business assessment, the degree to which the risk associated with a particular business deviates from the average risk delineation for the relevant industry is assessed.

In the business assessment, there are two significant sets of conditions, as follows:

1. The potential risk associated with the business;

2. The risk management of the business.

These two points must be seen in association with each other. We therefore propose that a simple matrix is used to achieve this objective, as follows:

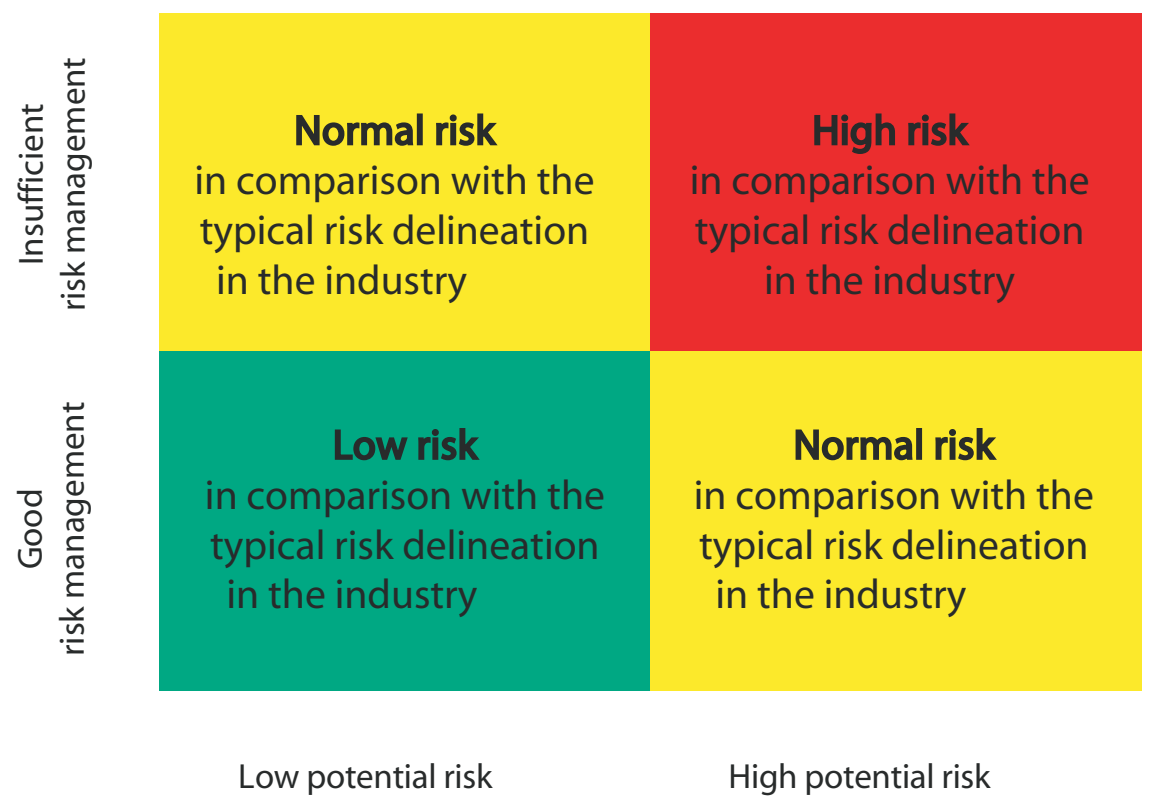

Figure 8. Assessment of business 
Additionally, particular control requirements in the legislation must be taken into consideration.

Operational official control personnel conduct the business assessments. The criteria for assessing which potential risks should be classified as high or low, or whether the risk management is insufficient or good, must be adjusted on a national basis, and the same applies to decisions on the results in the form of control time, monitoring frequency, fees or charges etc. Requirements regarding documentation of the assessments that have been performed must also be suitable for national systems.

\subsection{Potential risks associated with businesses}

When the concept of 'potential risk' has been used here, it refers to that risk that a business represents, should the actual hazards not be managed or kept under control.

In the assessment of potential risk, the following points should be made the subject of the assessment:

1. The product - that which is produced or marketed;

2. The production format - how the product is produced;

3. The size - the extent of all relevant activities;

4. Hazards in the surroundings - pollution, contaminants, wild animals etc. in the environment;

5. Complexity - the number of points where mistakes might occur;

6. Physical conditions - the premises, equipment etc.;

7. The use of production factors/contributory elements that could represent a risk, including imported items;

8. The vulnerability of the markets or the customers - public health risks for exposed groups, and the risk for transmission of animal diseases and plant pests to new areas.

\subsection{Risk management in the business}

In the assessment of risk management, the following points should be made the subject of the assessment:

1. Competence, including training;

2. Protection against the introduction of hazards - physical barriers, purchasing routines, reception and access controls;

3. Maintenance of premises and equipment;

4. Operating routines, including corrective routines should operating routines deviate from the norm;

5. The business's own monitoring and control of possible hazards; 
6. The ability and capacity of the business to manage undesirable events - track products, possible emergency or contingency plans;

7. Previous experiences with the business e.g. results from external certification/customer audits.

Potential risks will largely be associated with the operating situation of the business. This will usually be relatively stable. The risk management of the business will largely change as a result of new knowledge, changes in awareness etc. It is therefore the assessment of the risk management of the business that will be the most dynamic.

One item which should be taken into consideration, although it is difficult to set criteria for, is the capability and intent of the business to comply with the legislation. Assessment of competence and previous experience with the business are the factors that will probably provide most information on this.

\subsection{Implementation}

Businesses that belong to several industries are classified with respect to that industry with the highest risk classification. The risk classification of the business is assumed to be registered in the databases on the businesses. These data will be used as appropriate to plan the control activities. The individual authority will determine norms for the frequency and time of control. In some cases such norms will be established in the legislation or determined politically.

In some instances the existing data about a particular business will be so inadequate that it is not possible to give the business a risk classification. Such businesses should initially be classified as normal. If the risk classification has consequences to the extent of fees or charges, then this classification must be definitely followed (cf. the principles on presumption of innocence). However, in many cases, control of such businesses should be prioritised in order for knowledge about the business to be accrued.

In the control of individual businesses, the focus for official control or supervision determined by the industry assessment should be used.

The risk classification does not provide any guidance regarding type of control (e.g. audit, inspection, control drives). These are prioritised from other considerations. 



\section{Conclusion}

The project group believes that by using the model presented in this report, the requirements of EU-Regulation 882/2004 on risk-based official control can be achieved. The strength of the model is based in its systematic approach to risks, and the combination of several considerations and assessments that must be conducted at various levels. The individual control authorities must decide upon how this model is finally used. Irrespective of how the model is chosen to be used, it will be no mean feat to establish the model and adapt it to suit individual contexts. We urge everyone who uses the model to attempt to develop and adapt the model further in relation of their own circumstances and requirements. Using the model in different professional areas or problems, will involve confronting different difficulties and dilemmas that can be solved by different means. The project group therefore envisages that different authorities will use the model very differently from each other.

At the time of writing (December 2006), the EU-commission is developing guidelines for annual reporting on implementation of multi-annual control plans (cf. the EU-Regulation 882/2004). According to a draft, results from official control shall be reported, including those based upon analyses of experiences with the sections and links in the production chain. We believe that the structure that is presented in this report could also serve as a tool for this type of analysis. This is something that should be taken into consideration with respect to further development of the model.

Animal welfare risk is one risk that particularly requires further work. In this area, knowledge and information is especially limited. The concepts associated with animal welfare are elastic. Here there also seems to be a considerable requirement for improved clarification of the risk concepts, including those to be applied for positive and negative definitions of risk etc. At present some activity is in progress, under the guidance of EFSA, the research community, and among the authorities, to fill the gaps in our knowledge in this area. These include, amongst others, the project "the risks of poor welfare in intensive calf farming systems" (EFSA, 2006), that this report has used as a resource for obtaining some of its approach to animal welfare.

An appropriate and mature risk culture is the most important critical success factor for effective risk management, and that which is most frequently absent in organisations. Both research and experience indicate that individual attitudes, and attitudes that characterise organisations, have a significant impact on whether the risk management lives up to expectations. If efforts are only directed towards incorporation of new 
tools, techniques or streamlining of processes, it is probable that only marginal improvements will be achieved (Hillson and Murray-Webster, 2005).

What is regarded as critical, significant and insignificant, or what shall be considered to represent high or low risk, will often be assessed differently from group to group, and from organisation to organisation. Perceptions and attitudes to risks are also factors that should be worked with systematically, both at the group level and at the organisation level. This will increase the organisation's abilities regarding 'organisational selfreflection' and organisational training. Simultaneously with the implementation of the models for risk classification, it will also be of importance to work towards improving risk culture. 


\section{References}

Australia New Zealand Food Authority. 2001. Food Safety: The priority classification system for food businesses. Accessible from:

http://www.foodstandards.gov.au/_srcfile s/ANZFA_1578_Info_Paper_final.pdf

[Downloaded:13. November 2006]

Codex alimentarius. 2006. Food import control systems. CAC/GL 47-2003, REV.1-2006. Accessible from: http://www.codexalimentarius.net/web/st andard_list.do?lang=en [Downloaded: 19. January 2007]

Council for the European Union. 2000. Council Directive 2000/29/EC of 8 May 2000 on protective measures against the introduction into the Community of organisms harmful to plants or plant products and against their spread within the Community. Official Journal L 169, 10.7.2000, p. 1-112. Accessible from: http://europa.eu.int/smartapi/cgi/sga_doc? smartapi!celexapi!prod!CELEX numdoc\&lg=EN\&numdoc $=$ 32000L0029\&model=guichett [Downloaded: 1. December 2006]

EFSA. 2006. The risks of poor welfare in intensive calf farming systems - an update of the Scientific Veterinary Committee Report on the Welfare of Calves. Annex to The EFSA Journal (2006) 366 1-36. Accessible from:

http://www.efsa.europa.eu/en/science/aha w/ahaw_opinions.html [Downloaded: 8. December 2006].

European Parliament and Council of The European Union. 2002. Regulation (EC) No 178/2002 of the European Parliament and of the Council of 28 January 2002 laying down the general principles and requirements of food law, establishing the European Food Safety Authority and laying down procedures in matters of food safety. Official Journal L 031, 01/02/2002 P. 0001 - 0024. Accessible from: http://eur-lex.europa.eu/ LexUriServ/LexUriServ.do?uri= CELEX:32002R0178:EN:HTML [Downloaded: 15. November 2006]
European Parliament and Council of The European Union. 2004. Corrigendum to Regulation (EC) No 882/2004 of the European Parliament and of the Council of 29 April 2004 on official controls performed to ensure the verification of compliance with feed and food law, ani$\mathrm{mal}$ health and animal welfare rules (OJ L 191, 30.4.2004). Official Journal L 191, 28/05/2004 P. 0001 - 0052. Accessible from: http://eur-lex.europa.eu/ LexUriServ/LexUriServ.do?uri= CELEX:32004R0882R(01):EN:HTML [Downloaded: 13. November 2006]

FAO. 2003. FAO's Strategy for a Food Chain Approach to Food Safety and Quality: A framework document for the development of future strategic direction. Accessible from:

http://www.fao.org/DOCREP/MEETING/0 06/y8350e.HTM [Downloaded: 14. November 2006]

FAO/WHO. 1995. Application of risk analysis to food standards issues. Geneva: Report of the Joint FAO/WHO Expert Consultation. Geneva, 13-17 March. Accessible from:

http://www.who.int/foodsafety/publicatio ns/micro/march1995/en/index.html

[Downloaded: 26. November 2006]

FAO/WHO.1997. Risk management and food safety. FAO Food And Nutrition Paper 65, Rome. Accessible from: http://www.who.int/foodsafety/publicatio ns/micro/jan1997/en/ [Downloaded: 26. November 2006]

FAO/WHO.2006-1. Risk analysis framework. Accessible from: http://www.who.int/foodsafety/micro/risk analysis/en/ [Downloaded: 26. November 2006]

FAO/WHO.2006-2. Risk management. Accessible from: http://www.who.int/ foodsafety/micro/riskmanagement len/index.html [Downloaded: 26. November 2006]

FAO/WHO.2006-3. Proposed new definitions of risk analysis terms related to food safety-proposal from New Zealand. 
Accessible from: $\mathrm{ftp}: / / \mathrm{ftp}$.fao.org/codex/ ccgp23/gp23_09e.pdf [Downloaded: 26. November 2006]

Hillson, David and Ruth Murray-Webster. 2005. Understanding and Managing Risk Attitude. Aldershot: Gower Publishing Ltd

HM Government Cabinet Office Strategy Unit. 2002. Risk: Improving government's capability to handle risk and uncertainty. Report ref 254205/1102/D16, Crown copyright 2002. Accessible from: http://www.strategy.gov.uk/downloads/su /risk/report/downloads/su-risk.pdf

[Downloaded:14. November 2006]

ISO/IEC.1999. Safety aspects - guidelines for their inclusion in standards. Geneva: ISO/IEC Guide 51:1999(E)

ISO/IEC.2002. Risk Management - vocabulary - guidelines for use in standards. Geneva: ISO/IEC Guide 73

ISO 2005. Food safety systems - Requirement for any organisation in the food chain. Geneva: ISO/FDIS 22000:2205

(E)
Savadori, Lucia, Stefania Savio, Eraldo Nicotra, Rino Rumiati, Melissa Finucane and Paul Slovic. 2004. Expert and public perception of risk from biotechnology.

Risk Analysis, 24 (5): 1289-1299.

Statistics Norway. 2003. Standard Industrial Classification (SIC2002). Accessible from: http://www3.ssb.no/stabas/ ItemsFrames.asp?ID=3152101\& Language $=$ en $\&$ VersionLevel $=$ classversion\&MenuChoice=Language [Downloaded: 16.January 2007]

The International Plant Protection Convention. 1996. Guidelines for pest risk analysis. Roma: FAO ISPM Pub. No 2.

The World Organisation for Animal Health. 2005. Terrestrial Animal Health Code Accessible from: http://www.oie. int/eng/normes/en_mcode.htm [Downloaded: 26. November 2006]

Wikipedia. 2006. Accessible from: http://en.wikipedia.org/wiki/Animal_welf are\#The five_freedoms [Downloaded: 1. December 2006] 